\title{
LAS ISLAS CHAFARINAS ATRAVÉS DE LA CARTOGRAFÍA. DEL SIGLO XVI A LA OCUPACIÓN
}

SONIA GÁMEZ GÓMEZ

Profesora-tutora UNED

Instituto de Cultura Mediterránea

\section{LA CARTOGRAFÍA EN EL CONTEXTO MEDITERRÁNEO}

Las islas Chafarinas no formarán parte de la corona española hasta la mitad del siglo XIX, por ello, y ante la inexistencia o parquedad de otras fuentes documentales, uno de los instr umentos que van a permitir conocerlas durante los siglos anteriores es la cartografía. A través de esta documentación que podemos ver reflejada en difer entes formatos y tipologías (mapas, planos, portulanos, etc.) y realizada a veces, por aquellos países que en algún momento se sintieron interesados por ellas por cuestiones estra tégicas o políticas, podremos obtener innumerables datos acerca de la evolución y desarrollo de las islas en la historia. Por ello, la cartografía se ha convertido en instrumento de primer orden en el estudio de los precedentes a la conquista de este pequeño archipiélago.

\section{Los inicios de la cartografía}

Las islas Chafarinas forman parte de un escenar io que, aún a finales del siglo XVI, seguía destacando por su excepcional situación geográfica como centro neurálgico de la civilización moderna: el Mediterráneo, un lugar de encuentro e intercambio entre Europa y África, sin olvidar tampoco a Asia. A pesar del descubrimiento de nuevas tierras en otros continentes, el Mediter ráneo mantendrá un gran interés por parte de países que pretendían una posición hegemónica en el mundo.

La necesidad del hombre de buscar y colonizar nuevas tierras, muchas veces a tra vés del mar, propició el surgimiento de her ramientas que facilitaran estos desplazamientos y a vances. Para ello, la car tografía se convertirá en un instrumento esencial para estos mo vimientos incesantes. Sabemos que los an- 
tecedentes de la car tografía son remotos, las difer entes civilizaciones buscaron métodos para orientarse y calcular distancias o recorridos, en definitiva, localizar un lugar con la ma yor precisión posible y poder $r$ epresentarlo fielmente. Sin remontarnos tan atrás en el tiempo, serán los griegos los que inicien la geog rafía matemática en que se basan los mapas actuales. Posteriormente, sin haber aportado grandes innovaciones a la cartografía, la caída del Imperio Romano produjo una época de repliegue cultural hasta que los árabes tomaran la iniciativa para desarrollar su propio sistema entre los siglos VIII y IX que más adelante llegará a Europa a través de los intercambios comerciales. La elaboración car tográfica en los países europeos será tardía, pues no necesitaron abrir nuevas vías de comunicación y comercio mientras conservaron los tradicionales circuitos de comercio con Oriente.

Con la aparición de nuevos instrumentos técnicos, el Mediterráneo aportará importantes progresos a la navegación, entre ellos la proliferación de mapas y portulanos ${ }^{1}$, éstos últimos se desar rollaron durante el medie vo y habría que destacar los realizados por genoveses, venecianos y mallorquines, avances que serán aprovechados y utilizados más adelante por portugueses y españoles en sus descubrimientos hacia el Atlántico. La introducción a finales del siglo XIII de la brújula y el desarrollo del astrolabio generaron una mayor precisión y perfeccionamiento que se iba a reflejar en la elaboración de las pimeras cartas náuticas. Ya en el siglo XV, con la recuperación de las enseñanzas de Ptolomeo que se añaden a las técnicas de los portulanos, se innovará en la creación de nuevas y más precisas representaciones.

En este avance hacia el perfeccionamiento en el ar te de trazar mapas, se produce un punto de inflexión a mediados del siglo XVI con la llegada de Gerhardus Mercator y Abraham Ortelius², grandes cartógrafos que trabajaron en la corte del emperador Carlos V y Felipe II respectivamente. Con ellos comenzó una nueva era que acaba con la tendencia del siglo anterior.

${ }^{1}$ Las car tas portulanas o por tulanos se crean en el siglo XIII y tendrán un amplio desar rollo, incluso hasta la Edad Moderna, aunque su momento álgido está entre los siglos XIV y XVSon cartas que hicieron posible el uso de la brújula y pueden ser de dos tipos: las náuticas puras que r epresentan con detalle las costas mediterráneas y el Mar Negro; las náutico-geográficas que representan tanto el litoral como las zonas interiores. En su origen fueron cuadernos de rutas o instrucciones donde los navegantes anotaban los rumbos y las distancias entre los puertos.

${ }^{2}$ Gerhard Kremer cartógrafo y geógrafo de origen germano-holandés y natural de los Países Bajos españoles se convertiría pronto en un eminente cartógrafo que realizó trabajos para el emperador Carlos V. En 1554 se hizo internacionalmente famoso por la realización de un gran mapa de Europa. En 


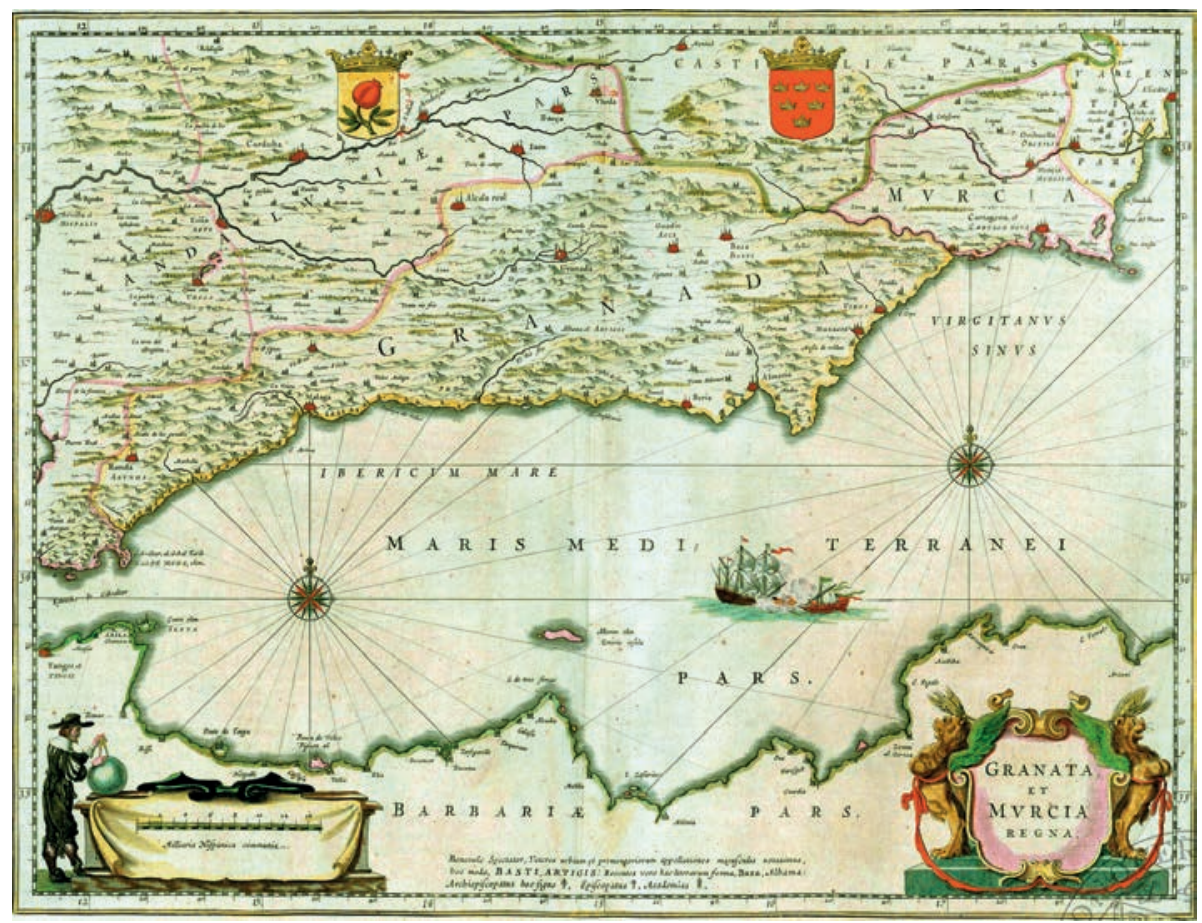

Granata et Murcia Regna. Mapa de Gerhard Kremer (Gerahardus Mercator) editado por Joan Blaeu en 1663. Comprende los reinos de Granada y Murcia. Pertenece a la colección Regiones de España de la Fundación Luis Giménez Lorente. Las islas Chafarinas aparecen dibujadas y denominadas I. Zafarinos.

En el XVII se establecen los principios técnicos básicos de la cartografía lo que determina que alcance $g$ ran perfección y se a vanza en su sistema tización, divulgación y tecnificación en las difer entes escuelas europeas. En el XVIII hay

1569 utilizaría el sistema de pr oyección de mapas, representación cilíndrica con meridianos rectos y paralelos y círculos de latitud iguales, con la ventaja de que la distancia más corta entre dos puntos en el globo está representada como una línea r ecta. Por esta razón, esta proyección se utiliza ho y día para navegar. Mercator, considerado uno de los mayores cartógrafos de la época de los descubrimientos, pues fue de gran valor para los navegantes la proyección que concibió para su mapa.

Abraham Ortelius, cartógrafo flamenco fue el autor del primer atlas moderno. Fue un famoso matemático antes de dedicar su actividad a la geografía y la cartografía. En 1570 publica Theatrum Orbis Terrarum obra innovadora de gran éxito comercial y, actualmente, se sigue usando la clasificación y estructura de éste. Su atlas tuvo gran aceptación tanto por su tamaño como por su formato, fue editado en varios idiomas y siguió actualizándose hasta 1612.En 1575 fue nombrado geógrafo de Felipe II un cargo que le permitió el acceso a los conocimientos acumulados por los exploradores portugueses y españoles. 
que hacer notar la impor tante aportación de los car tógrafos franceses, cuyos progresos serán secundados más adelante por los de otr os países, entre ellos Inglaterra, gracias a sus viajes de exploración. Más adelante, otros se aventuraron en nuevos estudios topográficos a gran escala, como sucedió durante el siglo XIX. La fotografía aérea, estudios geodésicos y otras innovaciones técnicas formarán parte de la cartografía del siglo XX, precisándola al máximo.

Todos estos avances y la proliferación de tanta documentación gráfica nos permitirán conocer las distintas $r$ epresentaciones que se hicier on de las islas Chafarinas durante los siglos XVI, XVII y XVIII hasta ser tomadas por España a mitad del XIX. Las Chafarinas ocupan un lugar estratégico a tan solo 3,2 km. de la costa norteafricana, en el Marruecos oriental próximo a la frontera de Argelia. El archipiélago está emplazado apr oximadamente a $46 \mathrm{~km}$. de distancia de la fortaleza de Melilla y sus coordenadas geográficas serán $2^{\circ} 26^{\prime}$ longitud oeste y $35^{\circ} 11^{\prime}$ latitud norte. Sin duda, será su posición geog ráfica la que provoque la ocupación a mitad del siglo XIX, un valioso emplazamiento defensivo que vendría a engrosar las posesiones de España en la costa africana con el objeto clave de asentar estratégicamente el papel de España en esta zona.

En las representaciones tempranas del siglo XVI estas islas serán dibujadas como una posición discreta del Mediterráneo occidental. Un pequeño archipiélago que, a pesar de sus reducidas dimensiones, es reproducido desde antiguo por cartógrafos occidentales en mapas generales de la costa afr icana y entorno europeo. Situadas a veces de manera imprecisa, gracias a estas descripciones gráficas observamos las difer entes formas en que fuer on denominadas. Fuera de este contexto general europeo-africano mediterráneo las vemos también representadas en vínculo dir ecto a la costa afr icana y a Berbería o el r eino de Fez, sobre todo en cartas esféricas específicas de mayor precisión descriptiva.

Las islas Chafarinas fueron apreciadas como un lugar de gran importancia para la defensa de la fortaleza de Melilla durante el siglo XVI, tanto por su posición geográfica como por la cercanía de ambas Por esta razón no es difícil hallarlas esbozadas en algunos diseños o dib ujos de la llamada Laguna de Melilla, la Mar Chica, o de la costa inmediata a esta ciudad. Algunos interesantes mapas de este siglo se encuentran custodiados en el Archivo General de Simancas (Valladolid) o en el Archivo General Militar de Madrid, determinando como por entonces formaba parte del conocimiento que las flotas españolas tenían de la zona occidental del Mediterráneo. 


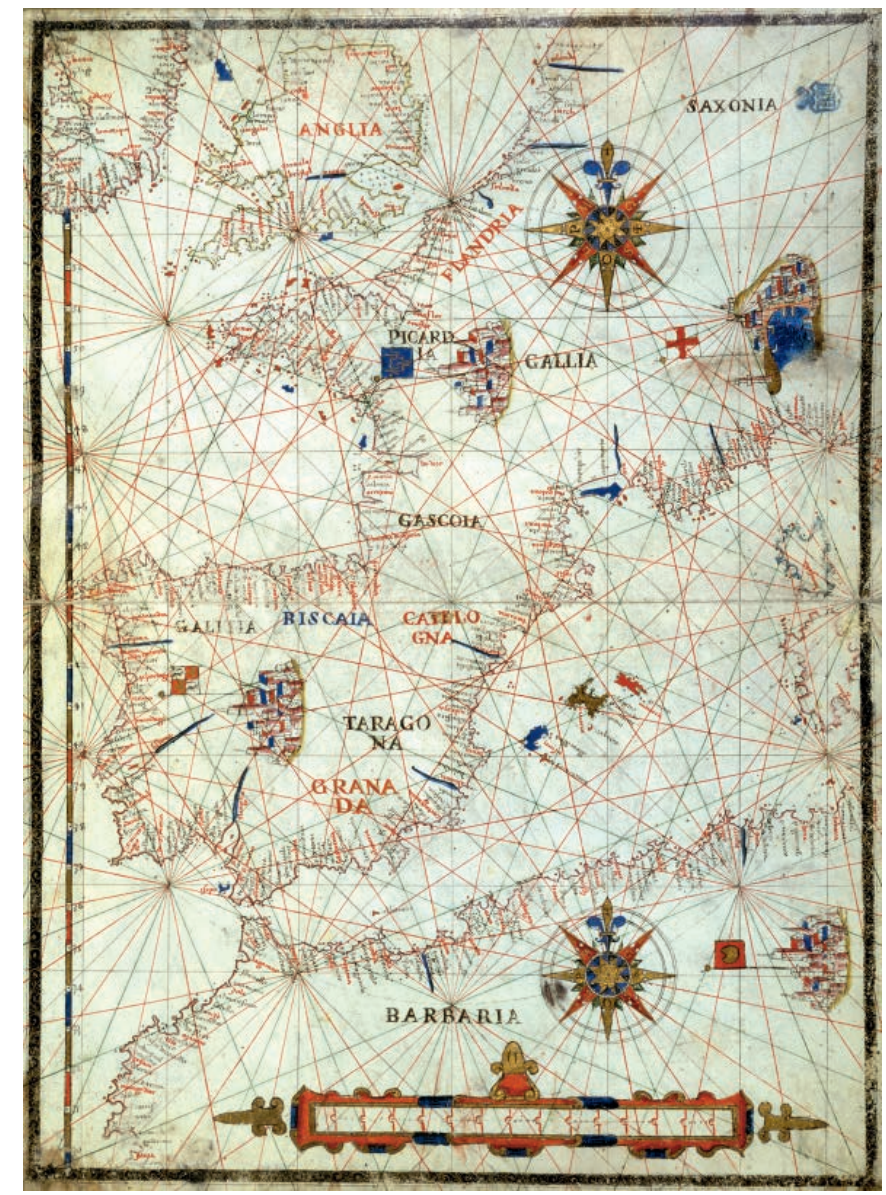

Carta náutica en pergamino deVicentius Demetrius Voltuis. 1592. Es un mapa del Mediterráneo que representa la parte más occidental de Europa, la costa atlántica africana y, por otro lado, la costa atlántica de España, Francia y parte de las islas Británicas. Tiene abundante toponimia en las costas y las ciudades más importantes están en rojo, el resto en negro. En su perfil impreciso de la costa norteafricana aparecen reflejadas las islas Chafarinas que son denominadas Iafarini.

Ya desde el siglo XVII contamos con planos más concr etos referidos a las islas, muchos de ellos asociados a los continuos y div ersos informes emitidos por distintas comisiones donde participaban acreditados miembros del Real Cuerpo de Ingenieros Militares, con el fin de considerar las necesidades de consevación de las posesiones de España en Áfr ica. Numerosas serán también las car tas náuticas de Chafarinas, muchas de ellas realizadas por comisiones francesas, aunque tenemos ejemplos de representaciones encargadas por Inglaterra y, por supuesto, España. 


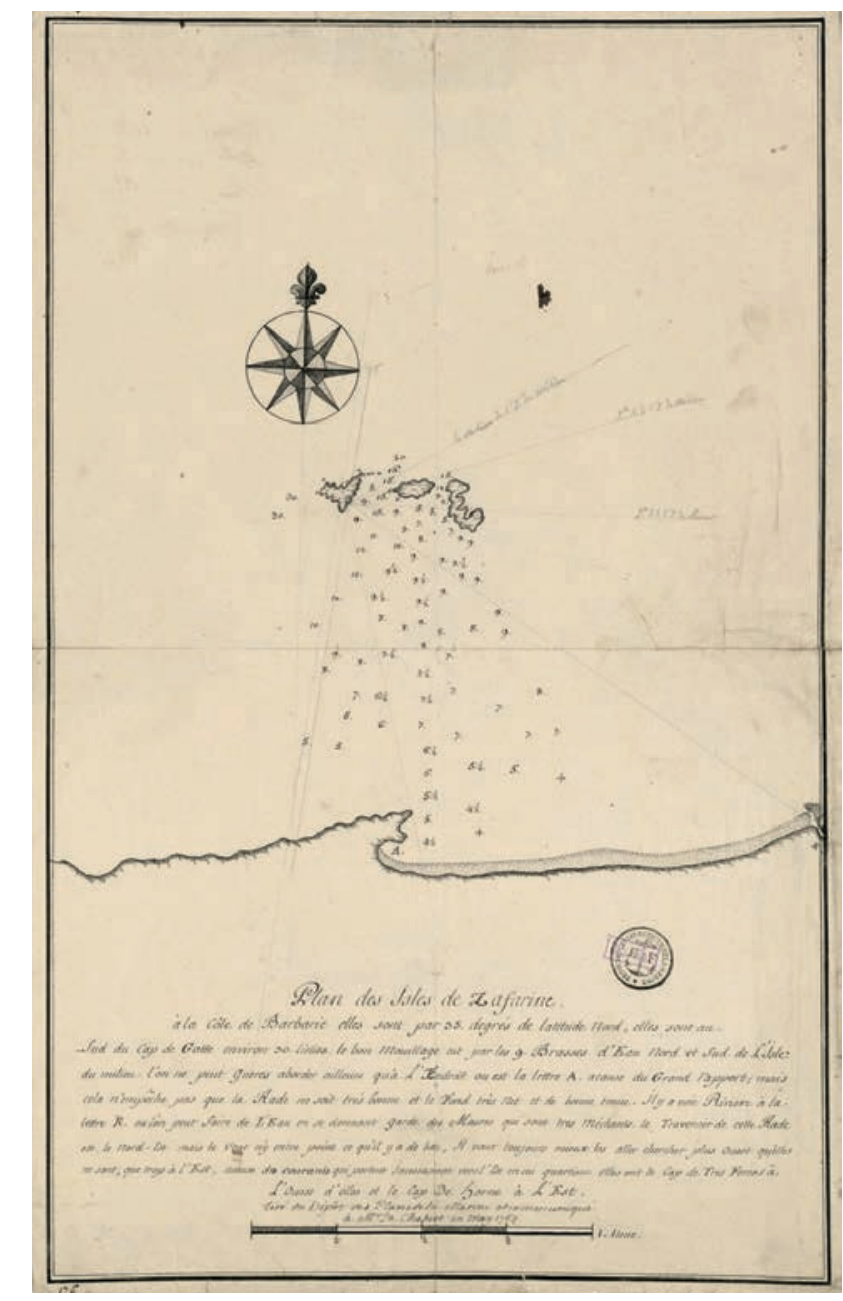

Plano de las islas Chafarinas de 1764 realizado por una comisión francesa.

\section{LA PRESENCIA ESPAÑOLA EN EL NOR TE DE ÁFRICA. LOS PRESIDIOS MENORES}

Las islas Chafarinas estuvieron habitadas en época neolítica y más tarde fueron conocidas por los naregantes antiguos, tanto fenicios como púnicos,también incluidas por los romanos en las rutas mediterráneas e itinerarios, como el de Antonino. Durante mucho tiempo quedaron deshabitadas y se con virtieron en un lugar de refugio para pescadores de la costa rifeña o navegantes sorpren- 
didos por los fuer tes temporales. Durante los siglos XVI y XVII este pequeño resguardo de embarcaciones fue despertando el interés de aquellos países que de soslayo cruzaban sus aguas, sin embargo, no será hasta el siglo siguiente, durante el reinado de Carlos III, cuando se produzca un planteamiento serio de la ocupación del archipiélago en un momento crucial para España.

\section{La conveniencia de conservar o abandonar los denominados Presidios Menores ${ }^{3}$. El siglo XVI}

En la segunda mitad del siglo XV los portugueses tomaron la iniciativa de expandirse hacia la costa atlántica africana, posición que afianzaron conquistando puntos estratégicos como Ceuta, Tánger o Arcila, entre otros. A finales del siglo, un momento decisivo para España que culmina con la conquista de Granada y la unión de los diferentes reinos hispanos, los monarcas españoles prosiguen la política expansiva de los lusitanos, lo que se ma terializa con la política norteafricana de los Re yes Católicos y del r egente Cisneros. En origen, estas intervenciones en la costa de África por parte de España estuvieron motivadas por múltiples factores tanto ideológicos, como económicos, aunque la necesidad de ocupar posiciones defensivas fue la que realmente determinó que España interviniera en el norte de África.

Antes de iniciar el salto definitiv o hacia la otra or illa del Mediterráneo se realizó una importante y cuidadosa ser ie de acuerdos y tra tados entre los reinos peninsulares para demarcar los límites de la expansión Este proceso iba a culminar en 1494 con el tra tado de Tordesillas, fundamental para la inmedia ta expansión mediterránea, pues, autorizaba a los Re yes Católicos a conquistar los pr imeros enclaves en el norte de África, Melilla y Cazaza primero y, posteriormente, continuar hacia nuevos puestos estratégicos. Sin embargo, en este tratado, se había reconocido también al reino de Fez dentro del ámbito portugués y, en este momento, a ellos se les ofrece la costa atlántica como camino a seguir para su expansión.

${ }^{3}$ El término Presidio equivalía a fortaleza, fuerte o bastión situado en los confines de un territorio, aunque, entre las diversas funciones que desempeñaba la for taleza, especialmente las fronterizas, estuviese el de ser vir de lugar de confinamiento debido a su configuración y pocas posibilidades de escapatoria. Entre los siglos XVI y XVIII estas fortalezas del litoral africano mediterráneo se distinguieron en mayores y menores, entre los primeros está el dob le presidio de Orán-Mazalquivir, Ceuta y Melilla; entre los menores destacar el Peñón de Vélez de la Gomera, isla de Alhucemas y, más adelante, formaría parte de éstos las islas Chafarinas. 
A través de la Bula Ineffabilis, el Papa Alejandro VI concede carta libre en 1495 a los Reyes Católicos para comenzar su expansión hacia África y el aporte económico necesario para ello. De esta manera se iban a materializar las primeras conquistas, entre ellas Melilla en 1497, Cazaza en 1506 o, posteriormente, en 1508 el Peñón deVélez de la Gomera que, perdido en 1522, se resistiría hasta su conquista final en 1564.

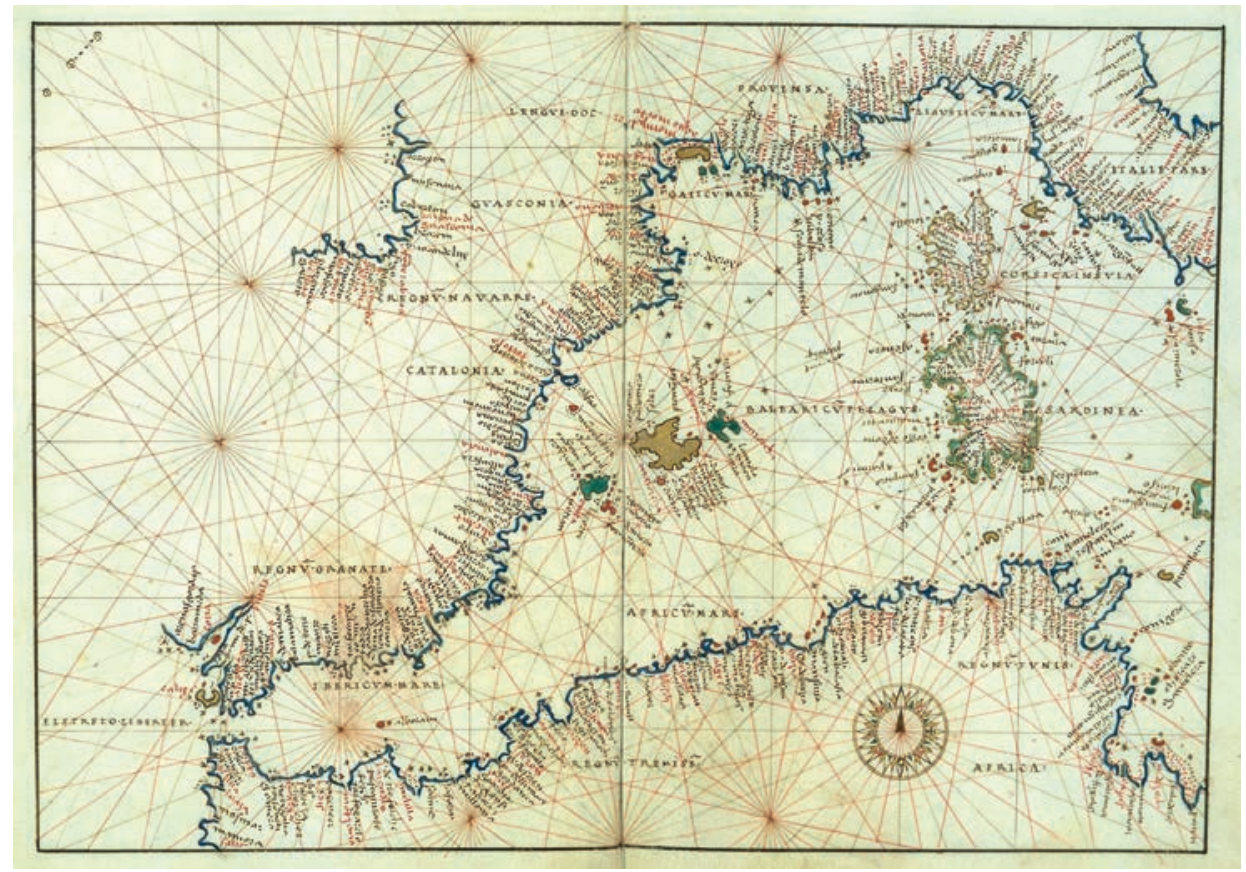

Plano del Mediterráneo occidental del año 1544 en el que las islas Chafarinas aparecen denominadas Jafarin.

Con la regencia de Fernando ${ }^{4}$ a principios del siglo XVI se producirán las primeras intervenciones en el norte de África. Pedro Navarro ${ }^{5}$ conquista Orán

${ }^{4}$ En este momento Fernando el Católico se alza de nuevo con la regencia entre los años 1507 y 1516, después de las tensiones generadas por la llegada de Felipe de Castilla y su intento de incapacitar a Juana. Sin embargo, las Cortes sólo reconocerán el nombramiento de la reina y Fernando como gobernador.

${ }^{5}$ Capitán e ingeniero militar español. Representa al ingeniero militar de la pr imera mitad del siglo XVI, con su actividad continua en campaña.Pedro Navarro se dedicó al corso por el Mediterráneo, causando grandes daños a los piratas, principalmente a los que operaban en el norte de África. Estuvo a disposición del Gran Capitán a cuy as órdenes estuvo durante las Campañas de Italia. En 1508 el r ey 
(1509), Bujía y Trípoli mientras se produce la sumisión de Argel (1510) lugares considerados frentes defensivos de España. Desde entonces se hicieron muy frecuentes los continuos reconocimientos en la costa mediter ránea africana pues estos enclaves adquirirían un indudable carácter defensivo y de sujeción o entorpecimiento ante cualquier tipo de acometida exter na al ter ritorio peninsular. Sin embargo, la llegada de Carlos I a España y el peso que los asuntos europeos iba tomando en la política exterior del Emperador, determinaron que esta primera idea se abandonase y se optara por una política menos costosa:el proyecto africanista se limitará a conquistar encla ves estratégicos en el litoral mag rebí mediterráneo, puntos for tificados alineados a tra vés de la costa for mando una barrera o frontera de defensa, un parapeto o línea defensiva para las costas españolas ante las amenazas turcas y berberiscas.



Política mediterránea de los Reyes Católicos ${ }^{6}$.

Fernando le ordena perseguir a los piratas berberiscos con una escuadra española después de asaltar las costas sevillanas y en esta operación conquistaría el P eñón de Vélez de la Gomera, en 1509 conquista Orán, campaña financiada por el cardenal Cisner os. Al siguiente año la campaña de Túnez le lleva a la conquista de Bugía y con elloArgel, Túnez y Tremecen se sometieron a la autoridad de España.Tras caer prisionero de los franceses en la batalla de Rávena en 1512 pasará al servicio de Francia, siendo considerado el iniciador de la escuela francesa de fortificación.

${ }^{6}$ Bravo Nieto, A. El Gran Capitán y la España de los Reyes Católicos, 2004. 
Los tanteos y expediciones por la costa afr icana van a generar numer osos informes que son redactados para conocer el estado de los presidios conquistados, diferenciados como mayores o menores y que ahora eran de soberanía española. Algunos de estos dictámenes describen minuciosamente la situación en la que se encontraban estas for talezas y hablan de las necesidades más inmedia tas de cada una de ellas, lo que permite hoy tener una visión clara y concisa de las deficiencias que existían, las dificultades a salvar o esfuerzos empleados para su mantenimiento y conservación. De momento, quedaba mucho tiempo para que el ardhipiélago de las Chafarinas perteneciese a España, aunque, por entonces, ya eran mencionadas por los antiguos geóg rafos españoles, como es el caso de Mar tín Fernández de Enciso ${ }^{7}$ que, en 1519 , en la primera impresión de su obra titulada Suma de Geografía, señala topográficamente lo que denomina como Isleos Jafarinos.

Con la llegada al trono de Felipe II en 1555, aún en guerra con Francia y las arcas extenuadas, se da un giro hacia el sur y el Mediteráneo reclamará su atención. Trípoli fue atacada por el virrey de Sicilia y, más adelante, continuarán las ofensivas contra Djerba (Túnez) y el P eñón de Vélez de la Gomera. Felipe II volcará su potencial económico y humano en el Mediter ráneo y este hec ho le impedirá imponerse en Flandes. De las primeras exploraciones que se llevaron a cabo de los intereses de España en la zona, hay constancia en 1567 de la relación que dio Juan Andrea ${ }^{8}$ al rey Felipe II sobre el Peñón, Melilla, Salinas, Laguna y África, hoy custodiada en el Archivo General de Simancas. Éste propuso abandonar Melilla, argumentando que estaba mal fortificada y era demasiado frágil si un fuerte ataque caía sobre ella. Doria insistió en arrasarla para que no pudiera ser ocupada por otros y explica el deficiente sistema defensivo que la protegía; de la misma manera, éste quita importancia a la rentabilidad de sus salinas situadas en

${ }^{7}$ Cartógrafo militar español nacido en Se villa. Desarrollará casi toda su car rera en las r ecién descubiertas Américas. Publicó en 1519

Suma de Geografía que tratará de los diferentes lugares del mundo. Los mapas se prohibieron por Orden Real para evitar su conocimiento y conflictos con Portugal.

${ }^{8}$ Sobrino del fallecido Andrea Doria, almirante y hombre de Estado genovés que pasó del servicio de Francisco I de Francia al de Carlos I de España en 1528. Juan Andrea Doria tomaría parte en la guerra con Francia al frente de sus galeras. Concurrió a la escuadra que se formó en 1562 para el socorro de Orán y Mazalquivir al mando de las galeras de Génova. Participó en la expedición de Vélez mandada por García de Toledo. Junto a Juan de Austria se unió a la expedición apresando algunos en ella algunos bergantines berberiscos. En 1601 mandó la expedición na val contra Argel pero su actuación fue duramente criticada. 
la Mar Chica. Esta exposición provocará una nueva interrogante, la incorporación o no de la laguna en el sistema defensivo de Melilla. Andrea Doria apuesta por una torre defensiva en las salinas y reforzaba su idea de que la laguna era más importante para repeler a una armada turca que pretendiera conquistar Melilla. Las islas Chafarinas también eran contempladas en esta cuestión, pues formaban parte importante del sistema estratégico de Melilla, siendo el archipiélago refugio de los grupos de corsarios que actuaban en la zona ${ }^{9}$.

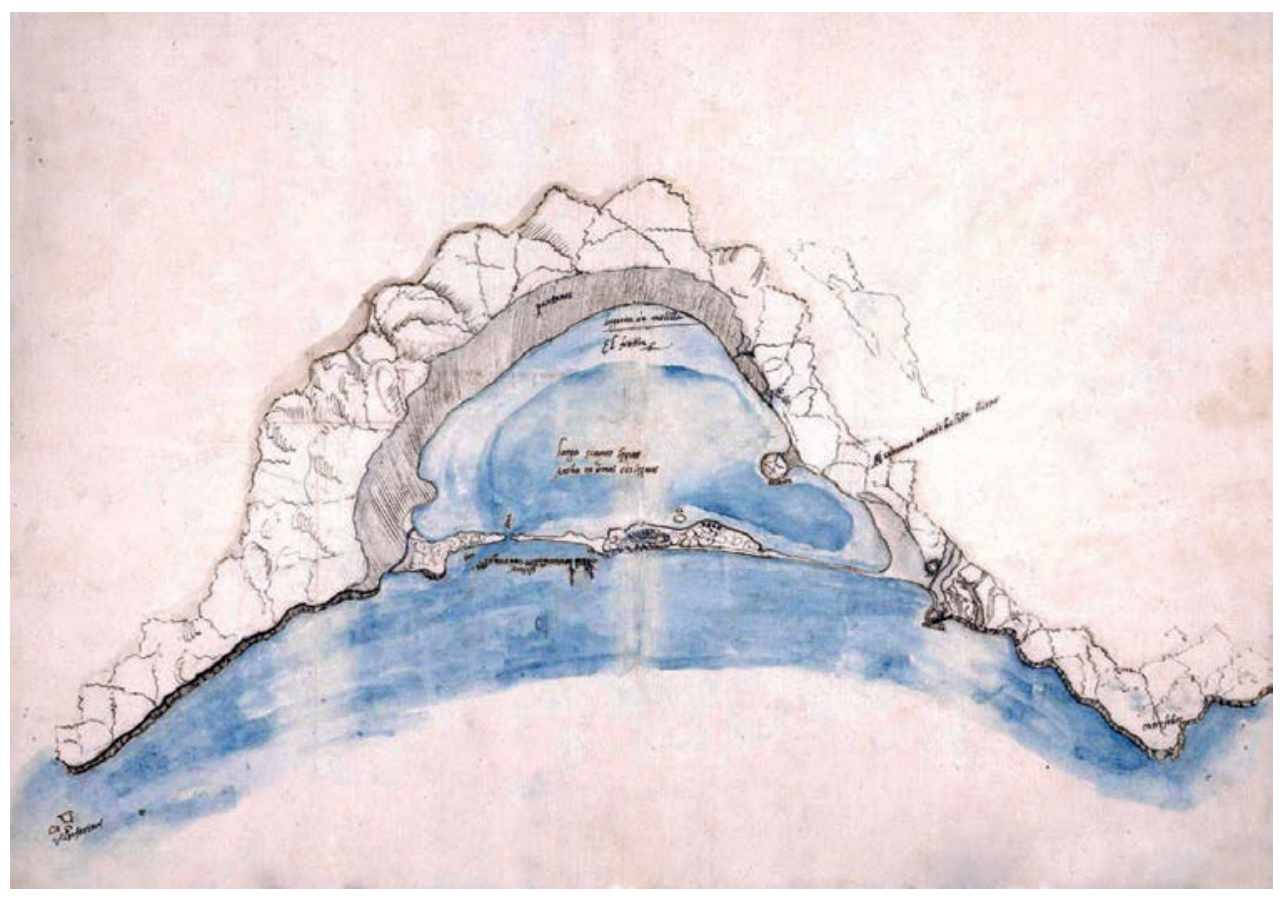

Representación de la Laguna o Mar Chica hacia el año 1564. Las islas Chafarinas aparecen reflejadas en el margen izquierdo, frente a la ciudad de Melilla. Archivo General de Simancas (AGS).

Durante el siglo XVI se irán perdiendo uno a uno los encla ves que tanto esfuerzo emplearon en conseguir los españoles, quedando únicamente en poder de España de forma continuada Melilla y el Reñón deVélez que será reconquista- 
do definitivamente con sus tierras inmediatas en 1564. Más tarde, 1687, la abundante documentación que generaban estas conquistas se vería incrementada por una nueva adquisición de España en la costa africana, la isla de Alhucemas. Tanto Melilla como Vélez de la Gomera y Alhucemas constituirán los denominados presidios menores, mientras que Ceuta y Orán (situados estrłégicamente en los extremos de esta línea de fortalezas) comprenden los presidios mayores.

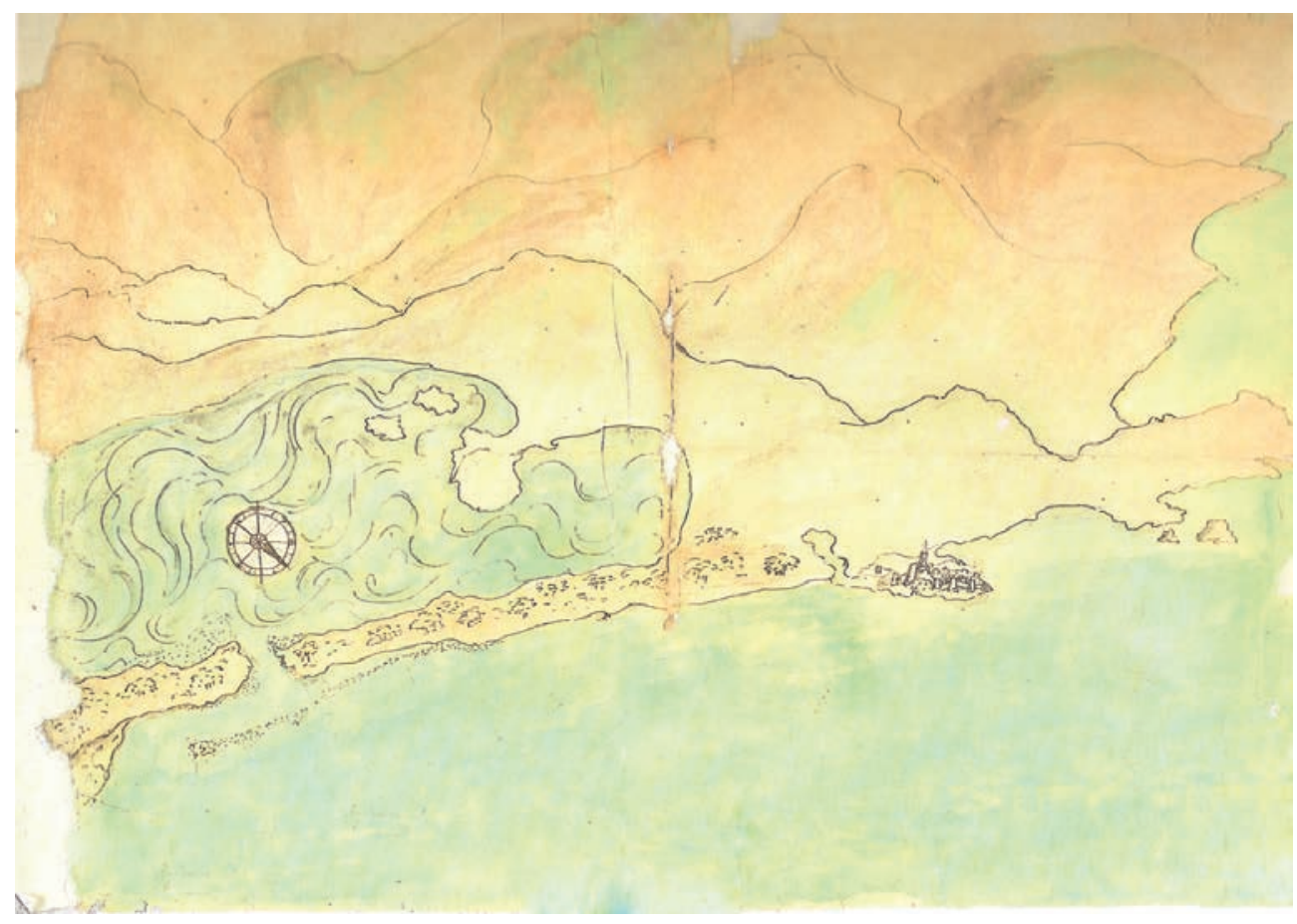

Diseño de la costa y laguna Mar Chica. 1564.AGS.

\section{Situación de los Presidios Menores. Los siglos XVII y XVIII}

Durante el siglo XVII se percibe de forma muy contundente la crisis que se vivía en España. Por entonces se perdían algunas posesiones hispanas situadas en la costa atlántica marroquí, y las que aún se conser vaban en la costa mediterránea se fortificaron para frenar la constante presión de Marruecos. Por ello se generaron continuos proyectos para su r eforzamiento y protección, mientras tanto, las islas Chafarinas mantenían su estatus estratégico, aunque todavía falta- 
ba mucho tiempo para que fuesen ocupadas permanentemente y pasaran a ser de soberanía española.

El siglo XVII se caracteriza por sufrir duros reveses, alejándolo de la época dorada que supuso el siglo anterior, cuando las tropas españolas eran imbatibles. La marina hispana en esta centuria se encontraba en plena decadencia y no consiguió destruir el peligro turco que mantuvo su presencia constante en las costas mediterráneas. Muchos factores repercutieron en el hundimiento del poderío naval, entre ellos el atraso técnico y la falta de materias primas.



Plano del siglo XVII que representa Melilla, y la Mar Chica, frente a ésta aparecen situadas las islas Chafarinas. AGS.

Una nueva dinastía se implanta con el comienzo de siglo; Felipe V es proclamado rey de España y con él llegan los Borbones Por estas fechas ya se encontraba en declive la idea de expansión y conquista del Mag reb, el peligro turco había desaparecido y las embestidas berber iscas estaban en decadencia, por lo que el desinterés por tierras norteafricanas fue en aumento. 
El enorme costo destinado a mantener aquellos enclares conquistados durante la empresa africanista junto con las dificultades y esfuerzos que generaban su defensa, iban a generar un amplio debate durante todo el siglo XVIII, sobre la conveniencia de conservar o abandonar los denominados presidios menores de África. Esta cuestión producirá discrepancias acerca de la necesidad de mantenerlos, debido al alto coste económico que suponía para España, sobre todo en momentos de crisis.

Mientras se debatía la cuestión de las posesiones españolas en Áfr ica, las islas Chafarinas, a principios del siglo XVIII, continuaban abasteciendo de leña y piedra a la ciudad de Melilla, siendo habitual enviar embarcaciones para tal cometido. En muchos de estos viajes surgían situaciones inesperadas,como en 1713 cuando al aproximarse una embarcación española para r ecoger madera apresó otra con una numerosa tripulación formada por berberiscos y numerosas mercancías. Otras muchas veces, los barcos con su tripulación llegaban arrastrados hasta las islas por los temporales quedando su personal en ellas, como la primavera de 1719 en que tuvieron que salir a rescatar a los que quedaron en el archipiélago después de ser desplazados hasta allí por un fuerte temporal.

También, en algunas ocasiones, las islas fueron destino de ocio para la población de Melilla, a pesar de que, a veces, podían ser sorprendidos por los temporales que suelen azotar la zona de for ma repentina, provocando el rescate desde Melilla. Estos viajes hacia Chafar inas, aún en los inicios del siglo XVII, también corrían el riesgo de ser interceptados por los cor sarios ingleses que operaban en la zona, siendo conducidos inmediatamente después hasta las islas con el fin de pedir rescate para su liberación. En algunas ocasiones la situación se tornaría complicada para el gobernador de Melilla, momento en que no llegaba a ser suficiente la recaudación impuesta por los corsarios.

Una nueva propuesta es planteada en 1731 por el conde de Aguilar, ésta consistía en emplear a las cua tro órdenes militar es españolas en los pr esidios (Alcántara, Calatrava, Santiago y Montesa) aunque no llegó a tener trascendencia alguna en la cuestión que se venía tratando. En estos momentos era de major interés confirmar el estado en que se encontraban estos territorios, por lo que fueron continuos los reconocimientos y abundantes las descripciones que de ellos se hicieron. Gracias a estas minuciosas reseñas hoy podemos conocer cuál era la situación de estas pequeñas for talezas. En 1733 se r ealiza un reconocimiento de Juan José 
Navarro, Marqués de la Victoria, que en esta fec ha era comandante del na vío de guerra San Fernando. Éste recibiría una orden expresa de reconocer las islas mientras se encontraba en plena acción en Orán. En este primer reconocimiento de Navarro se describía el puerto de las Chafarinas como un excelente fondeadero.

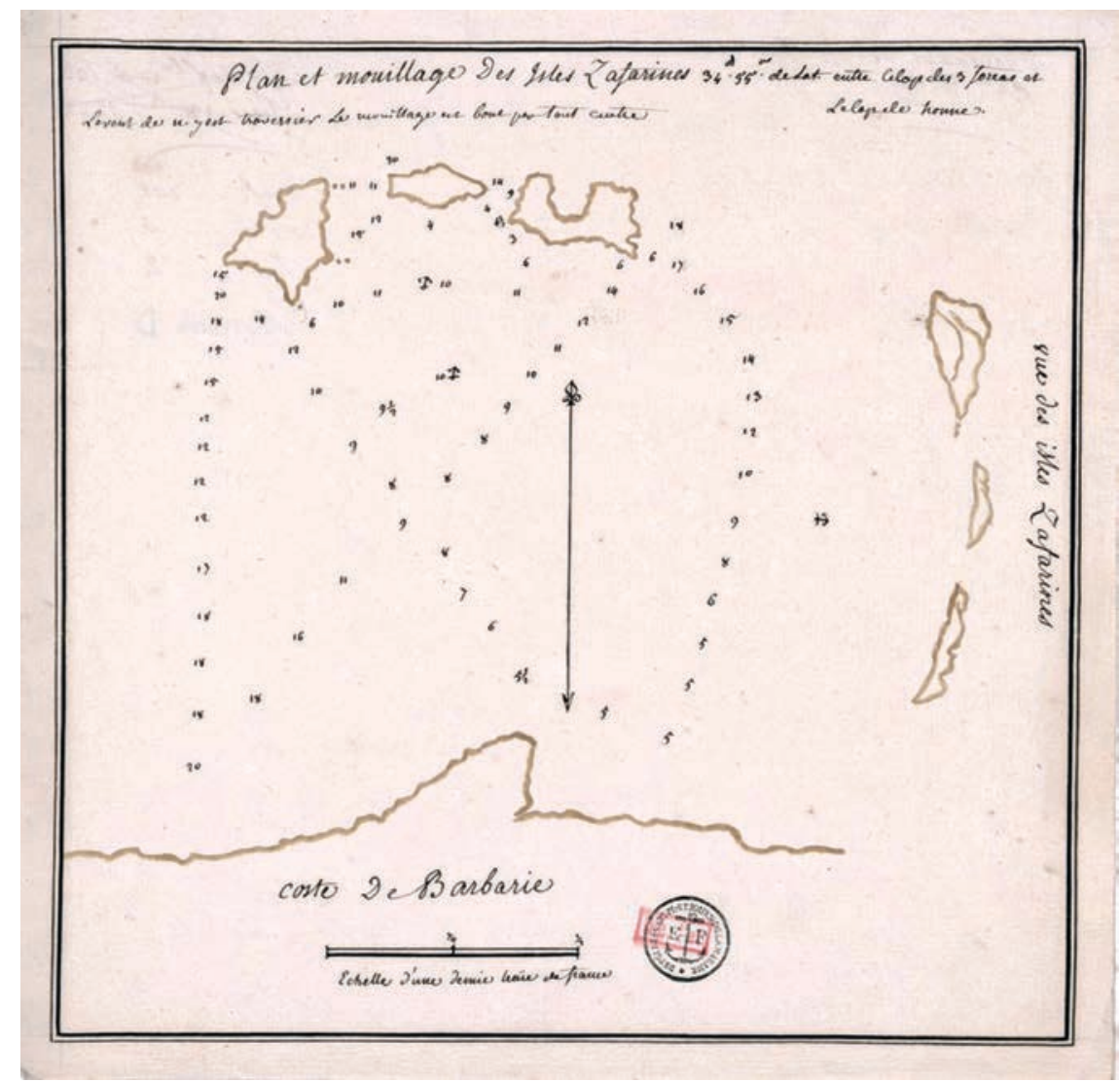

Plano de las islas Chafarinas, Zafarines, realizado por Francia en el año 1776.

Así lo describe también en 1749 la comisión for mada por un oficial, dos ingenieros y el capitán de mar ina Pedro Justiniani que será acompañado en el reconocimiento de la costa africana por el coronel de ingenieros Matheo Vodopich y el teniente coronel Segismundo Font. La comisión estaba destinada a visitar e inspeccionar los diferentes presidios en África con el objetivo de analizar la conveniencia o desventaja de continuar en ellos. Las conclusiones inmediatas de la comisión llevaron a anunciar el beneficio y las ventajas de ser demolidos y, para 
ello, buscar los medios adecuados para evacuar la artillería, pertrechos, tropa y familias que los ocupaban. La delegación concluyó haciendo una valoración sobre la importancia de inutilizar aquellos sitios cegando sus puertos, calas y abrigos para impedir su reutilización y evitar que el reino de Marruecos o cualquier otro estado se beneficiara del abandono.

A través de la cartografía realizada de la época podemos observar el interés suscitado por otras potencias europeas hacia el ardipiélago de las Chafarinas mientras España continuaba con sus incesantes reconocimientos y posibilidades de ocupación. Por ejemplo, encontramos numerosos planos realizados por comisiones francesas que intentan $r$ eflejar con minuciosidad los contor nos de las islas y su situación geográfica frente a las costas africanas. Otros ejemplos lo protagonizan Inglaterra, Italia oAlemania que, en algún momento de su historia vieron la posibilidad de ocupar las islas, consideradas como avanzadilla de la costa norteafricana.

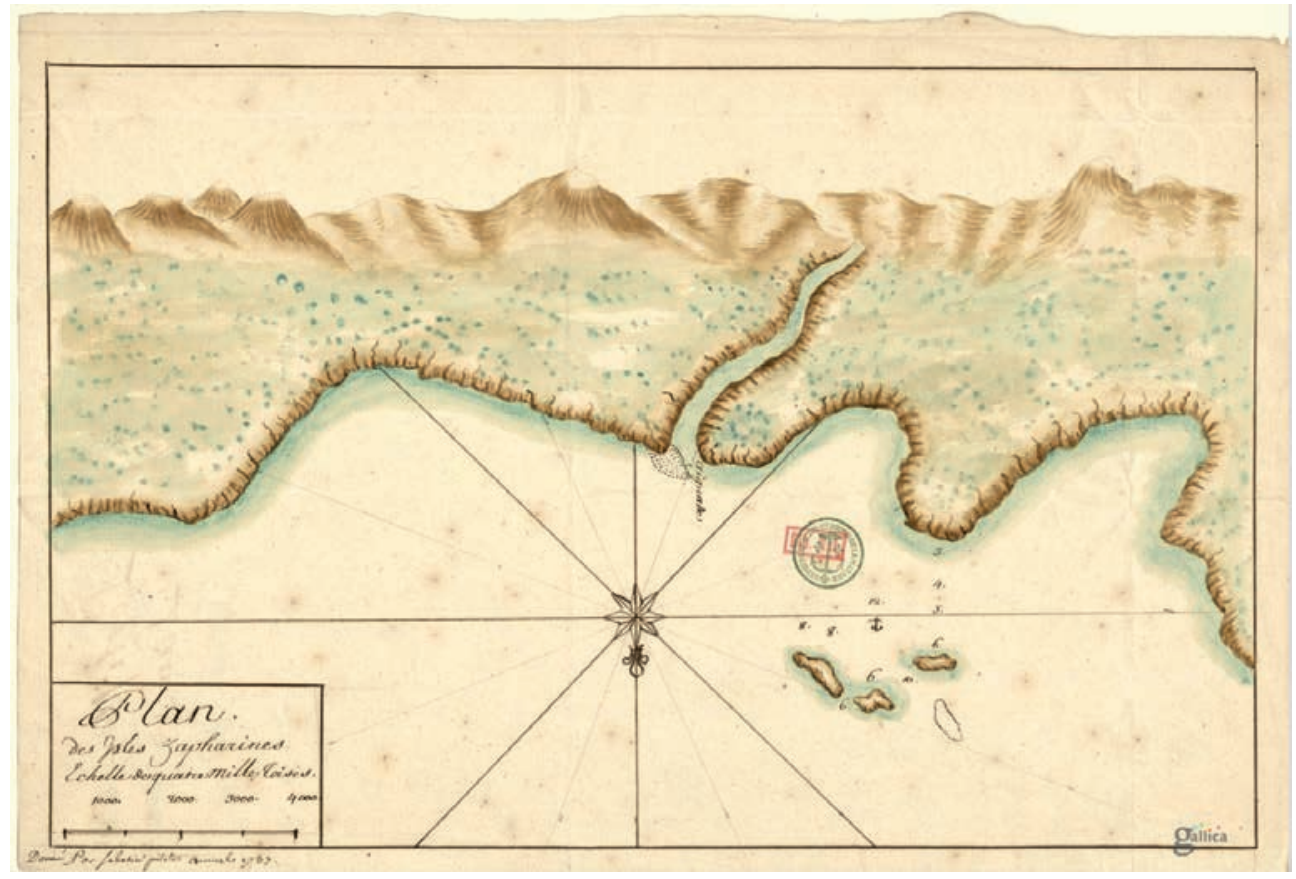

Plano de las islas Chafarinas realizado por Francia en 1737, es interesante el detalle con el que se intenta representar a las islas pues, de forma esbozada, han querido reflejar lo que se conoce como la cuarta isla o Laja que se encuentra sin emerger a poca profundidad. Biblioteca Nacional de Francia. BNF 


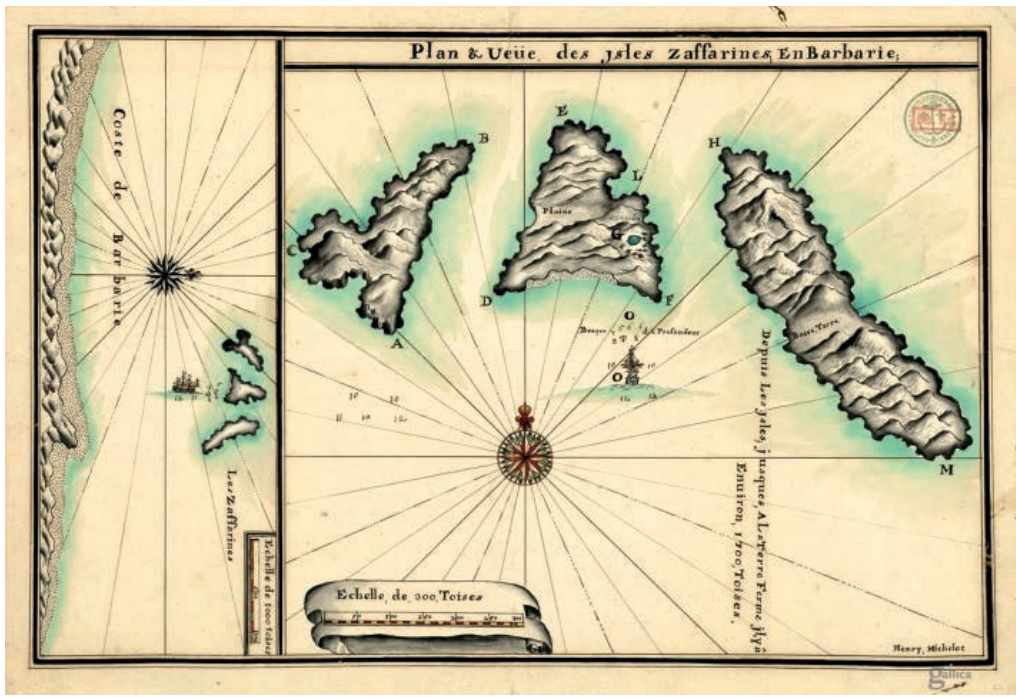

Plano y vista de las islas Chafarinas en Barbarie de Henry Michelot ${ }^{10}$ de finales del siglo XVII. BNF

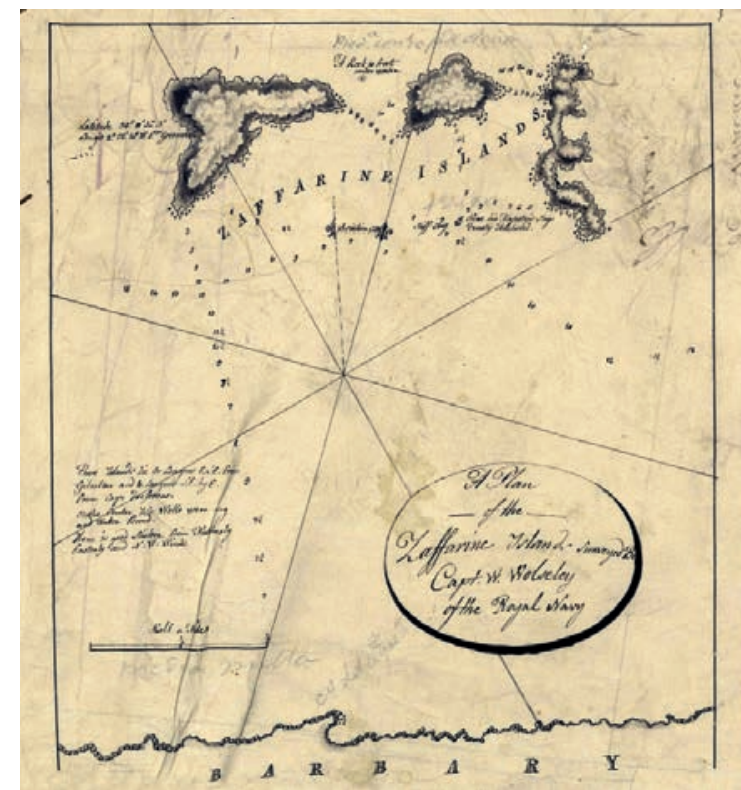

Zaffarine Island, plano realizado por el capitán W. Wolselcy de la Marina Real inglesa en 1700. BNF.

${ }^{10}$ Hidrógrafo y piloto de las galeras del r ey de Francia. Realizó una ser ie de atlas y mapas del Mediterráneo que han sido consideradas como las representaciones más científicas realizadas entre finales del siglo XVII y principios del XVIII. 
Es interesante apreciar hasta este momento como, a la vez que se cuestionaba el mantenimiento de los presidios menores conquistados, se mantenía la decisión y continuaban las propuestas, cada vez más firmes, de conquistar las islas Chafarinas. En el año 1761 el capitán general de la Armada y marqués de la Victoria, Juan José Navarro, hará un reconocimiento de las islas Chafarinas y las conquistas africanas pertenecientes a España.Su resolución final se reduce a advertir que Melilla, Peñón de Vélez y Alhucemas debían ser abandonadas y destruidas, trasladar la población a las islas Chafarinas y fortificarlas para su protección. En su informe también proponía el abandono de Orán, aunque no su destrucción. Obviamente, esta propuesta no fue apoyada y una nueva expedición en 1766 por el ilustre marino, matemático y cosmógrafo españolVicente Tofiño ${ }^{11}$, hizo de las islas objeto de estudio en uno de tantos viajes realizados, coincidiendo por esta época con los rumores de que Francia tenía la intención de ocupar el archipiélago. Si bien, no fue así, no iban mal encaminadas las historias sobre las intenciones francesas.



Plano de finales del siglo XVIII en el que se representa la Plaza de Melilla frente a las islas Chafarinas y junto a la Laguna de la Mar Chica. Depósito General Topográfico de Ingenieros.

En 1763 las nuevas instrucciones para el reconocimiento de los presidios menores aportan datos sobre la situación y circunstancias de la costa de Áfr ica concerniente a las plazas tomadas. Felipe Caballero coronel y teniente del rey en

${ }^{11}$ Fue miembro de la Academia de la Historia. Elaboró un Atlas Marino de España, islas Azores y adyacentes entre 1775 y 1788. Publicó una colección de cartas esféricas de las costas de España y África, planos y vistas en 1788. Participó en la expedición contra Argel en 1773. 
Cartagena, el coronel de ingenieros Mateo Vodopich ${ }^{12}$, el capitán de navío Pedro Justiniani y el teniente coronel de ingenieros Segismundo Font, en sus respectivos ministerios, fueron comisionados por Real Orden para esta misión ${ }^{13}$, donde finiquitan exponiendo que no existe ninguna conveniencia en mantener los presidios; tampoco beneficio alguno en el aumento del comercio ni sirven de freno a las incursiones en las costas españolas;proponen aumentar la guarnición y considerar el gravamen en mantenerlos. El informe describe detalladamente cómo deberían hacer el desmantelamiento de los presidios para que quedasen inutilizados en caso de que fuesen tomados por los beeberes. Relatan para cada uno de ellos la de sus puer tos y la demolición de las for tificaciones y demás edificios interiores. Un trabajo que debía ser realizado por minadores, maestros oficiales, tropa y presidiarios. El informe concluye haciendo una estimación del gasto que supondría lo propuesto teniendo en cuenta la demolición, el abandono y la evacuación de los tres presidios. Este dictamen fue realizado por los cuatro peritos teniendo en cuenta el asesoramiento del reedor de Málaga, Miguel de Monsalve, que paradójicamente se encontraba a fa vor del mantenimiento de los pr esidios exponiendo sus ventajas a la Secr etaría de Guerra en el memor ial económico que ésta le había encargado Las ideas conservacionistas de Monsalve fueron apoyadas por el veedor del Peñón de Vélez de la Gomera, Martín de Córdoba. Las diferentes opiniones expuestas por los peritos por un lado y el veedor de Málaga por otro, en cuanto a la cuestión de los pesidios, producirá mayor confusión a la Secretaría de la Guerra, pues ambas posturas exponían razones de peso para sus propuestas. En julio de 1764 para aclarar la cuestión de las diurgencias recientemente expuestas se solicita otr o informe que según Muñoz Corbalán ${ }^{14}$ podría ser del ingeniero Antonio Gaver que ya había dictaminado con los mismos argumentos en 1749. Lo que hizo Ga ver fue básicamente analizar las dos posturas

\footnotetext{
${ }^{12}$ Vodopich, Matheo. Relación y descripción individual del presidio y plaza de Melilla.Comisión de Real Orden, en 23 de julio del 1763.

${ }^{13} \mathrm{El}$ resultado de esta comisión fue el extenso informe que firmó Mateo Vodopich. Las funciones del equipo quedan divididas de la siguiente for ma: Mateo Vodopich, ayudado por Segismundo Font, se dedicó al peritaje de las fortificaciones y de la artillería; Pedro Justiniani para las cuestiones de las costas y; Felipe Cavallero.

${ }^{14}$ Muñoz Corbalán, Juan Miguel: Estrategia de la corona española para la conser vación de los presidios menores africanos durante el siglo XVIII, ponencia elaborada básicamente a partir de la documentación existente en el Servicio Histórico Militar de Madrid, concretamente en su Catálogo General de Documentos.
} 
expuestas, decantándose hacia el lado de los v eedores de Málaga y Vélez de la Gomera. A partir de aquí, el informe de Vodopich, Justiniani, Font y Caballero quedaría prácticamente anulado y sin apoyo.

Las diversas resoluciones presentadas hasta ahora ante la cuestión del mantenimiento o abandono de los Presidios menores llevó al Ministerio de la Guerra a buscar dictámenes de la mano de per sonajes de mayor prestigio y con alguna vinculación o relación con dichos enclaves. Para ello se encargó un informe a dos ingenieros militares Pedro de Lucuze y Pedro Martín Zermeño ${ }^{15}$ en 1765, ambos pertenecían al Real Cuer po de Ingenieros Militares de España y van a responder a las sentencias hec has anteriormente por Vodopich y Font, apostando por el mantenimiento de las posesiones afr icanas (sobre todo de los pr esidios mayores de Orán y Ceuta) argumentando la necesidad de per manecer en ellas para una mejor defensa de España.

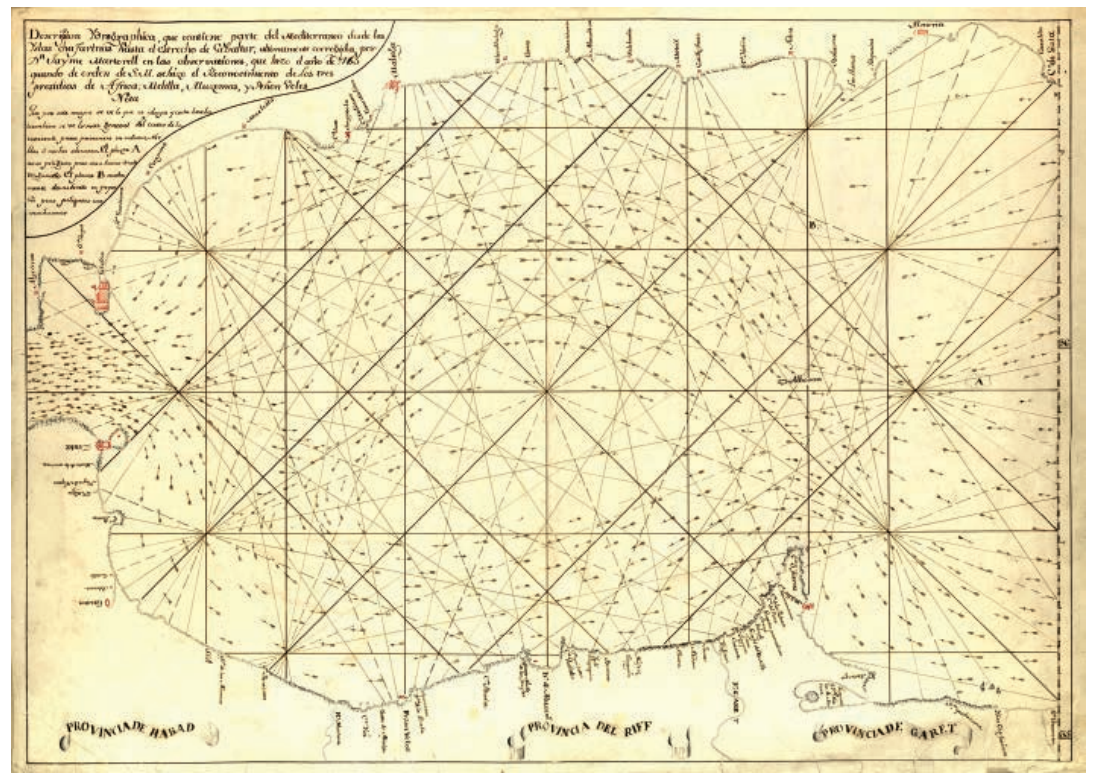

Descripcion Ydrographica que contiene parte del Mediterraneo desde lasYsla Chafarinas hasta el estrecho de Gibaltar, últimamente corregido por Don Jayme Martorell en las observaciones, que hizo el año de 1763 quando de orden de S.M. se hizo el Reconocimiento de los tres presidios de Africa; Melillla, Aluzemas y Peñon Veles.

\footnotetext{
${ }^{15}$ Pedro de Lucuze y Ponce, director de la Real Academia Militar de Matemáticas de Barcelona entre 1736 y 1779 y director y comandante del ramo deAcademias Militares desde 1774. Se convertirá
} 
Varios levantamientos de planos realizados por el capitán de fragata Vicente Doz iban a resaltar el importante carácter que iban adquiriendo las islas, en 1773 realiza un detallado mapa de las islas frente a las costas africanas en la que señala el cabo Chafarinas, lo que actualmente es Cabo delAgua. Dos ejemplos interesantes lo encontramos en planos de 1791 y 1796 en los que se buscaba la minuciosidad señalando los límites de la isla que nunca emergió y que se encuentra entre las dos islas más orentales en su extremo norte. Se le conoce como la cuarta isla o Laja pues se encuentra a muy escasa profundidad de la superficie.

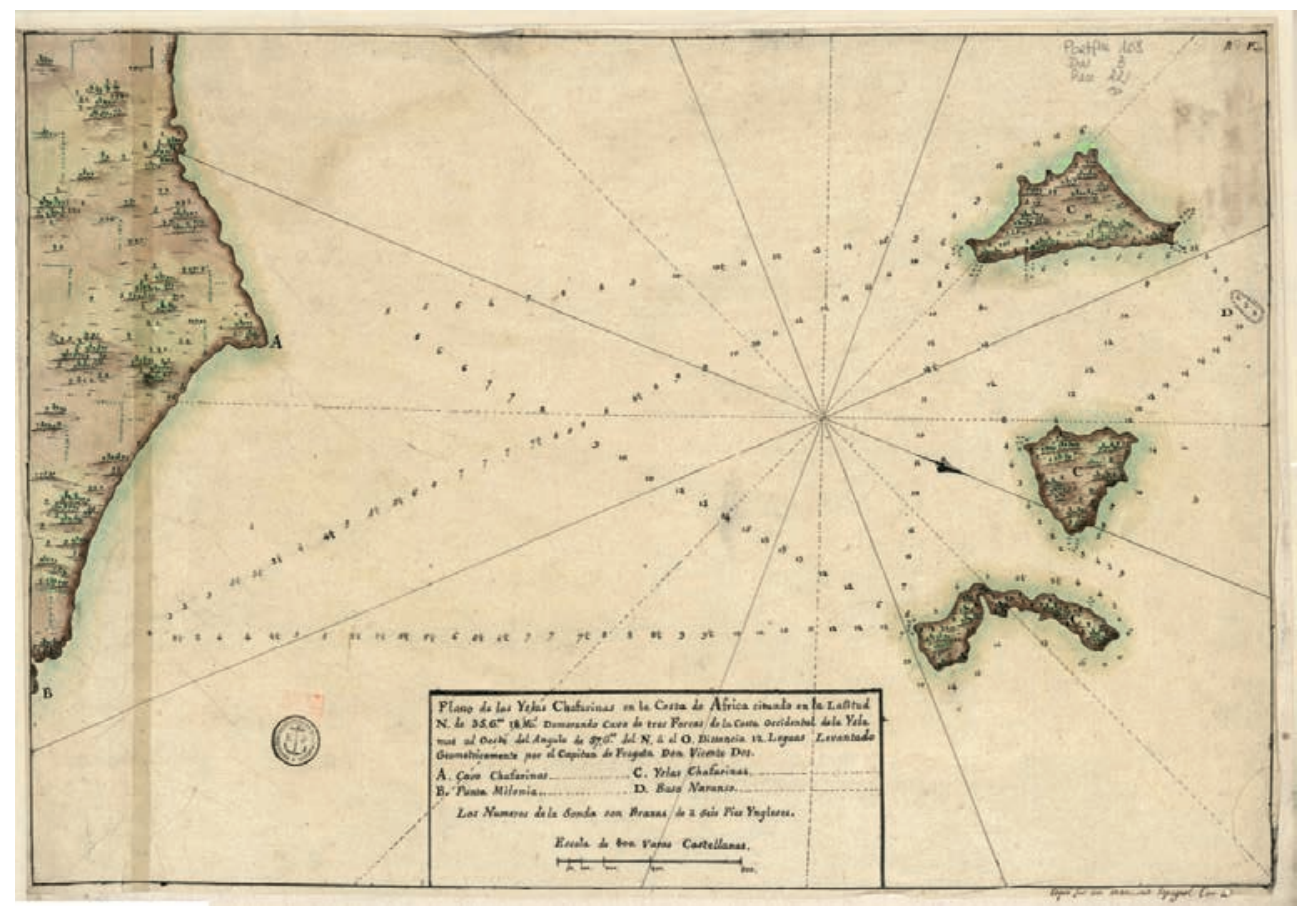

Plano de Vicente Doz realizado en 1796 donde el actual Cabo del Agua es denominado Cabo Chafarinas.

en una figura de g ran importancia en la ciencia española del siglo XIII por la impor tancia de su labor docente y su influencia en la formación de los ingenieros militares y otros oficiales del ejército.

Pedro Martín Zermeño, hijo de Juan Mar tín e Ingeniero Director del Principado de Cataluña. Proyectó la iglesia de Sant Miguel del Port de Barcelona (1753) y la catedral nueva de Lérida. Entre los años de 1776 a 1778 completó la urbanización de la Rambla barcelonesa. 
En 1774 llega la propuesta de ocupación permanente de las Chafarinas por parte de Francisco Hidalgo de Cisner os ${ }^{16}$, jefe de la expedición mandada por Carlos III para auxiliar al mar iscal de campo Juan Sherlok en el momento que defendía la plaza de Melilla del asedio puesto por el sultán Sidi Mohamed ben Abdallah. Cisneros acompañado de Antonio Barceló, que mandaba la Escuadra Ligera de Jabeques, aconsejaron dirigirse a las Chafarinas el tiempo que durara el asedio. Durante los años de 1774 y 1775 las islas Chafrinas sirvieron de refugio a la Escuadra por lo que llegó a considerarse la posibilidad de fortificarlas, reconociendo así su valor para una futura posesión.

En 1775 el dictamen del teniente general Silvestre Abarca, ilustre ingeniero militar, describe la situación de las islas Chafarinas y Melilla deduciendo el mayor beneficio para España la ocupación de las islas que el mantenimiento de la fortaleza de Melilla. En este mismo año el teniente general de mar ina Pedro González de Castejón ${ }^{17}$ realizó un plano de las islas Chafarinas situadas frente a la costa de Áfr ica y un dictamen sobr e el reconocimiento hecho de orden de su majestad Carlos III,de la situación de las islas Chafainas. Para esta exploración fue acompañado por los tenientes generales del ejército Antonio Ricardos, conde de O’Reilli, y el mariscal de campo comandante de ingenieros del ejército Silvestre Abarca, cuyo plano levantaron los oficiales de marina Vicente Tofiño, Felipe Mazarredo y Felipe Varela por su parte y los ingenieros del ejército por la suya. Dos dictámenes más de los militares Antonio Ricardos y Silvestre Abarca de 1775 y 1776 respectivamente expondrán sobre la conveniencia de establecerse en las islas Chafarinas y las ventajas de fortificarlas en detrimento de mantener Melilla.

${ }^{16}$ Marino profesional formado en las nuevas pautas de la Armada Ilustrada del siglo XVIII. Participó en la campaña del Nor te de África frente a los buques corsarios argelinos. Llevó a cabo diversos transportes de tropas para la defensa de Melilla, luego se unió a la flota del almirante Redro González de Castejón en el ataque directo sobre la ciudad de Argel.

${ }^{17}$ Marino y militar español que desar rolla su carrera entre Europa, América y África. En 1775 dirige una escuadra para atacar Argel y más adelante fue nombrado Secretario de Estado de Marina. 


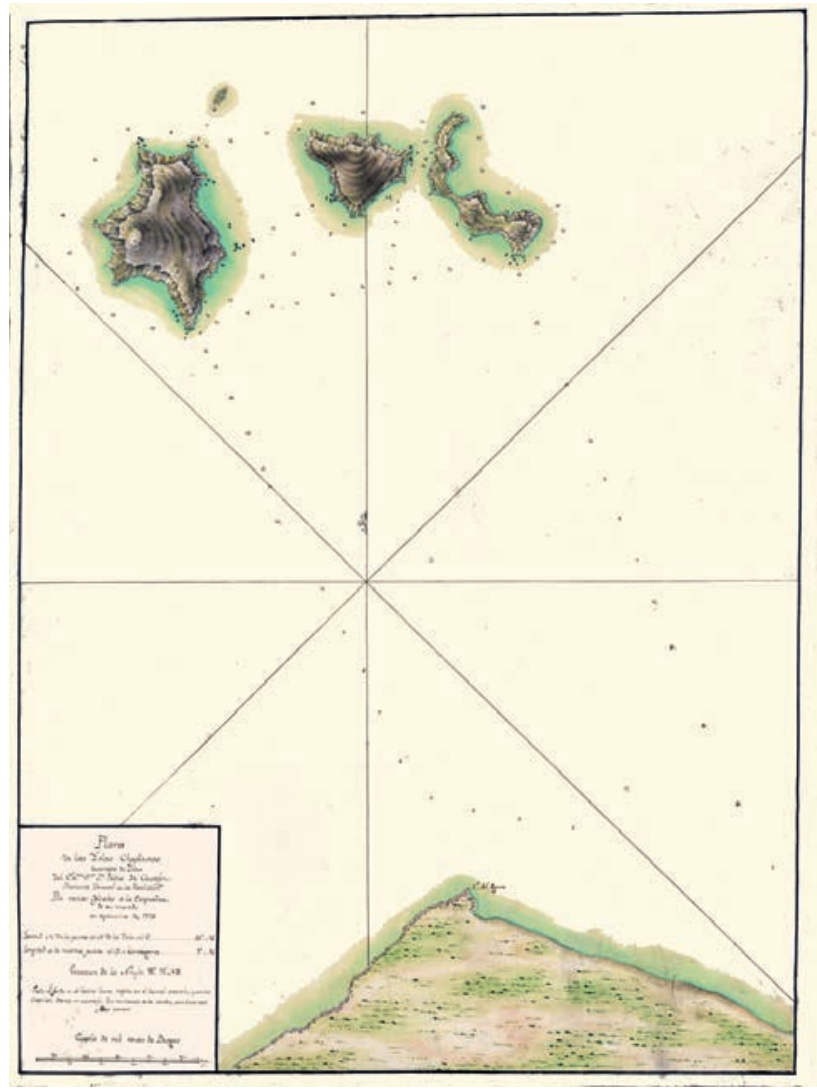

Plano de las islas Chafarinas levantado por Pedro de Castejón, teniente general de la Real Armada, varios oficiales de la Escuadra de su mando en septiembre de 1775. Existen varias versiones de este plano realizadas por Castejón durante la expedición.

Continuaron hasta finales del siglo XVIII las difeentes reflexiones sobre la cuestión y en 1794, por orden r eal, el capitán de ingenier os Fernando Pérez levantaría un plano de las islas Chaf arinas en un nue vo reconocimiento de las mismas. Alrededor del año 1776 el rey Carlos III va a disponer que se levanten bajos relieves de todas las Plazas y Fortificaciones de España y sus ad yacentes capaces de Defensa. En esta época de continuos y constantes cambios la función de estos planos en relieve de ciudades determinadas sería primordial para la seguridad de los estados que se hallaban en continuas disputas, por lo tanto, van a adquirir un carácter eminentemente militar. Para empezar, estuvieron entre los primeros trabajos elegidos las maquetas de los tres presidios menores de Melilla, Peñón y Alhucemas. La posibilidad de poder conocer con detalle las ciudades o posesio- 
nes más lejanas de la Nación iba a favorecer la proliferación de estos relieves en reconocimiento de los beneficios que apor tarían en los procedimientos militares de la época. El arquitecto Francesco Saba tini ${ }^{18}$ va a encargar a Alfonso Jiménez, capitán del Regimiento de Infantería de la Princesa que realiza los primeros trabajos, el levantamiento del bajo r elieve de las islas Chafar inas ${ }^{19}$. En la maqueta se representa un modelo de fortificación de las tres islas que forman el archipiélago, Congreso, Isabel II y Rey Francisco. Este bajo relieve será el precedente de futuros trabajos de mayor envergadura, como el famoso bajo relieve de la ciudad de Cádiz realizado entre 1777 y 1779, y fue depositado en el Real Sitio de Aranjuez, aunque, actualmente se desconoce su paradero.

La abundante producción cartográfica aporta interesantes datos acerca de las islas y la costa más inmediaa. A partir de un amplio período cronológico que abarca desde 1664 a 1796, podemos encontrar planos en los que se menciona o epresenta una ciudad del mismo nombr e en la costa afr icana frente al archipiélago. Planos realizados por los difer entes países europeos que deseaban mantener su presencia en el Mediter ráneo, franceses, ingleses, alemanes o italianos, también españoles, van a situar la ciudad de Chaf arinas en la costa con denominaciones como Zafarinos, Zafarin, Zaferina o Ciudad de Jafaria. Igualmente, un documento custodiado en el Archivo General de Simancas, Informe sobre varios aduares y puertos, entre ellos las islas Chafarinas, Taraga, Orán y Vélez de la Gomera, hace referencia a un aduar llamado de los Al Jafarines que se sitúa frente a las islas del mismo nombre.

Hay que destacar el plano que realizó en el año 1788 Tomás López $^{20}$, geógrafo y car tógrafo español, de las islas Chafarinas en el Mar Mediter ráneo. En él representa también las posesiones de Orán y Mazarquivir en el litoral afircano y hace una detallada descripción de las construcciones levantadas en estas Plazas. El mismo autor realiza un plano en 1793 de la ciudad de Melilla con una lgenda donde sitúa todas las obras defensiv as levantadas hasta el momento. En él se dibuja la línea del litoral africano, desde el caboTres Forcas hasta Cabo del Agua y frente a éste las islas Chafarinas.

\footnotetext{
${ }^{18}$ Francesco Sabatini (1722-1797). Arquitecto italiano que desarrollará sus trabajos en España al servicio de la Casa Real.

${ }^{19}$ Martínez Montiel, Luis F: La maqueta de Cádiz, algunos apuntes sobre la construcción y su autor.

${ }^{20}$ Tomás López realiza el Atlas Geográfico de España que comprehende el mapa general del reyno y los particulares de sus provincias en 1804. También Mapa general que comprehende los reynos de Marruecos, Fez, Argel y Túnez, en el año 1775.
} 


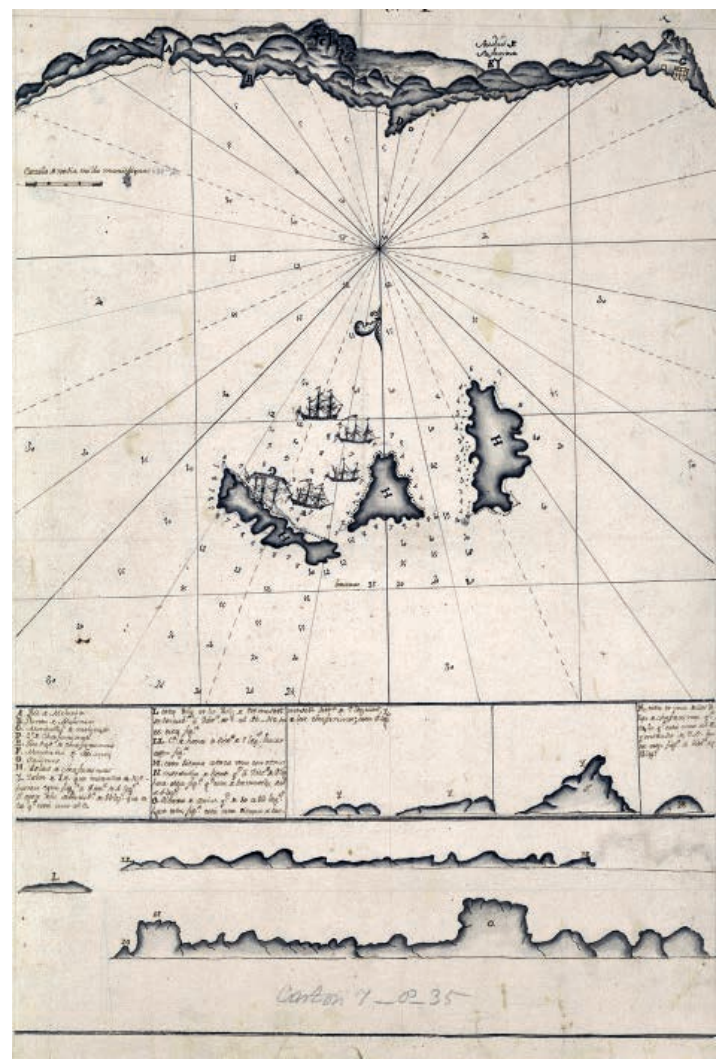

Plano de 1700 de las islas Chafarinas y la costa africana donde se ubica una ciudad o asentamiento denominado ciudad de Jafarinas. BNF.

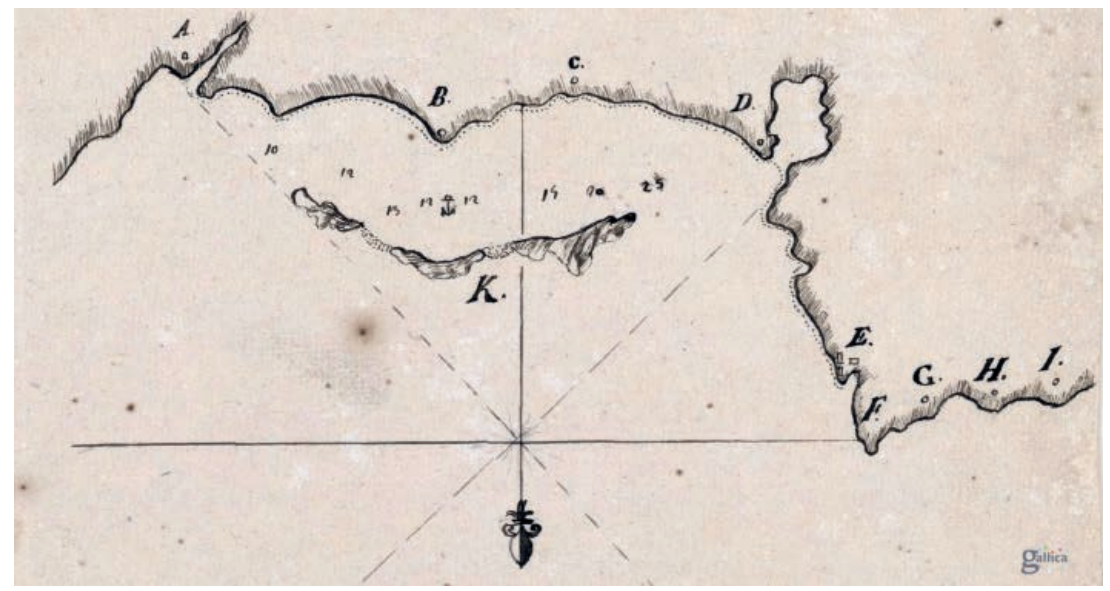

Plano de las Chafarinas donde se representan las islas y la ciudad del mismo nombre en la costa en 1741. BNF. 




Detalle del plano de Tomás Gómez de las islas Chafarinas en el Mar Mediterráneo realizado en 1788 . Centro Geográfico del Ejército.

Se inicia un nuevo siglo y las disertaciones, como la de Antonio Samper en 1810, sobre la conser vación o no de los pr esidios de África continúan. En la Memoria militar sobre la inutilidad de los Presidios Menores de África de 1821 de Juan Pérez ${ }^{21}$, se exponen los difer entes puntos de vista que deben tener se presente para el establecimiento de las plazas de guerra a lo largo de la frontera o costa y se hacen cálculos sobre el presupuesto necesario para el mantenimiento de estos recintos. Mientras tanto, las islas Chafarinas se convertirán en fuente de materias primas para la población de Melilla, y sobre todo se extraían piedras o madera empleadas en las construcciones que se desarrollaban en la fortaleza. A veces, se aproximaban hasta sus costas para obtener moluscos, pesca o mariscos y, según Gabriel de Morales, a principios de este siglo, se utilizaron como refugio ocasional de gibraltareños, hecho no constatado y de difícil cr edibilidad debido a la inexistencia de agua potable en el archipiélago.

\footnotetext{
${ }^{21}$ Ingeniero militar.
} 


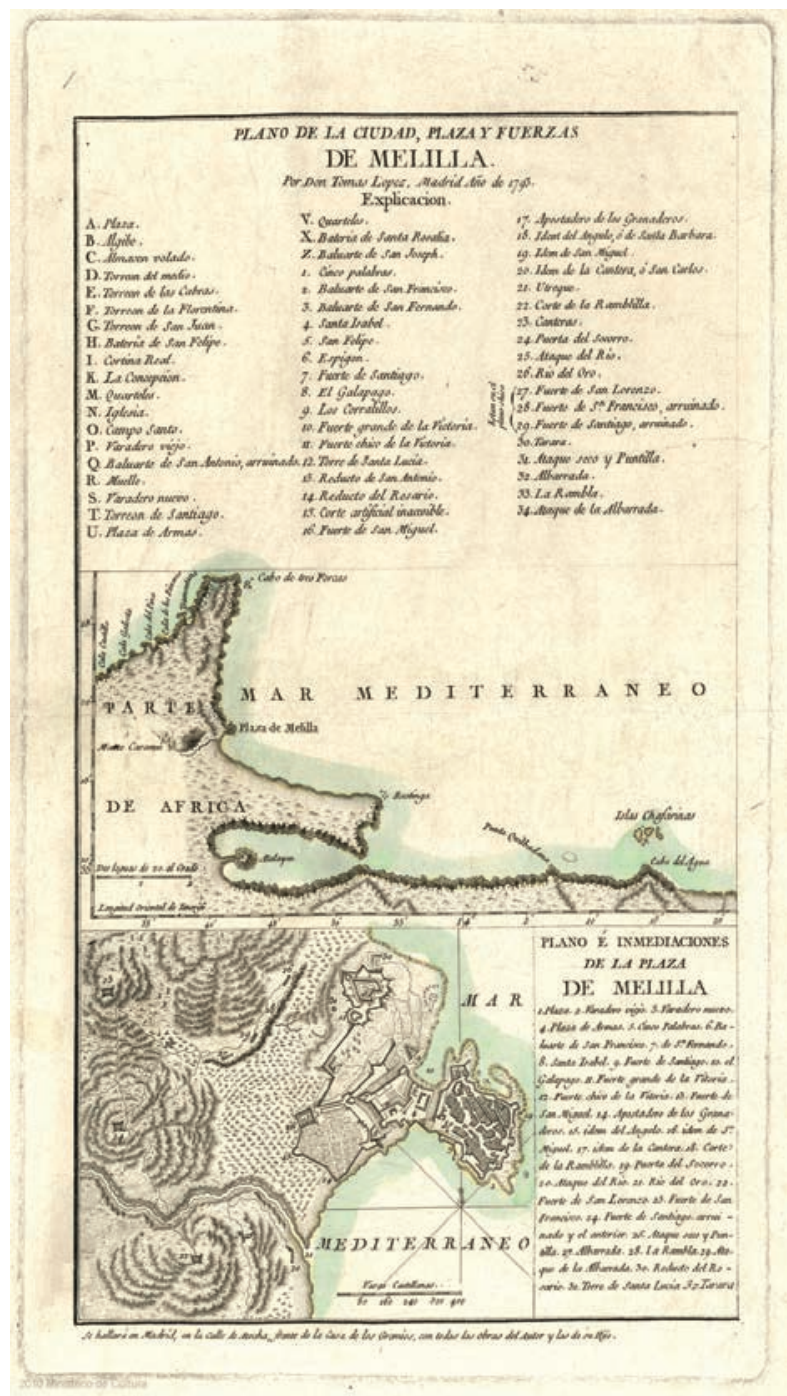

Plano de la ciudad, plaza y fuerzas de Melilla, por Tomás López en 1793.

En 1830 una comisión francesa de carácter científico que đேcorría el litoral de Argelia y Marruecos llegaría a las islas para $r$ efugiarse de un temporal, el grupo estaba constituido por algunos na turalistas como Ber thelot y Weble y, durante la visita, al suponer que las islas no habían sido nominadas, le asignaron a cada una de ellas los sobrenombres de Buckland, Busch y Brongniart homenajeando a tres ilustrados naturalistas. Durante su estancia aprovecharon para hacer algunas investigaciones científicas en el archipiélago. 

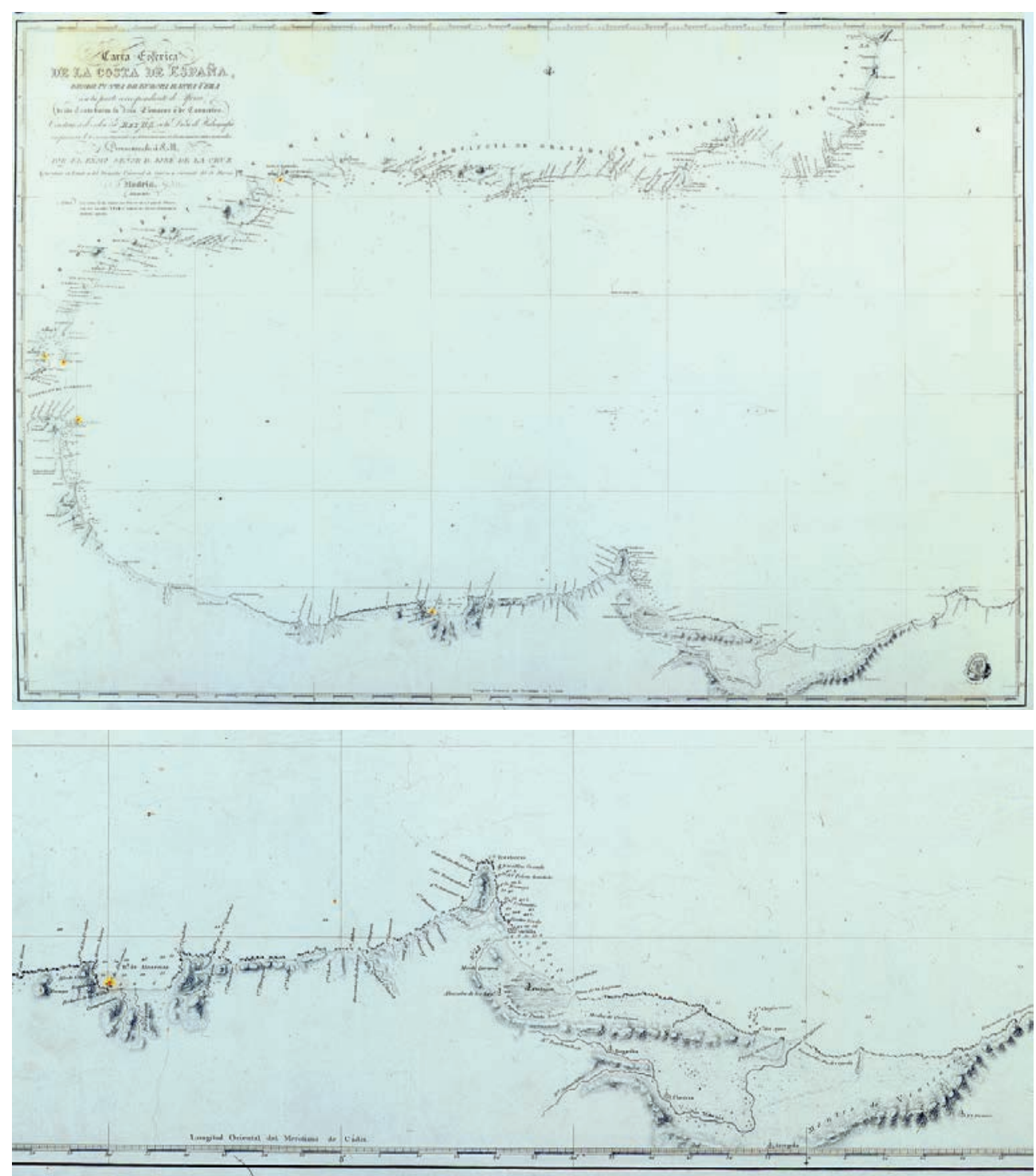

Carta esférica de la costa de España desde Punta de Europa hasta Vera con la parte correspondiente de África, desde Ceuta hasta la isla Limacos o de Caracoles. Realizado por José de la Cruz, secretario de Estado y del Despacho Universal de Guerra y encargado del de Marina. 1833

En 1839 se presenta un proyecto de mejoras aplicables a los presidios de África. El propósito era que aquellas plazas pudieran sostenerse en adelante con sus propios recursos y que produjeran a la nación rentas anuales y otras ventajas positivas. El documento fue presentado al gobierno de la reina Isabel II por un 
oficial empleado en la Inspección General de Infantería. A la propuesta acompañaban tres planos de Melilla y sus inmediaciones; y los estados que representa el coste actual de los tres presidios menores.

Para el año 1847 se había creado la Capitanía General de las Posesiones de África, que comprendería Ceuta, Peñón, Alhucemas y Melilla, posteriormente, una vez ocupadas las islas Chafarinas pasarían a formar parte de esta institución. En 1851 la Capitanía sería suprimida, por lo que Melilla pasaría a depender de la Capitanía General de Granada como Comandancia General. Un Real Decr eto de 22 de marzo de 1893 estableció la división militar de la Península en 7 Regiones y 4 Comandancias Generales; las Comandancias dependían directamente del Ministerio de la Guerra, y una de ellas era Melilla (incluyendo los presidios menores: Alhucemas, Chafarinas y Peñón de Vélez de la Gomera) ${ }^{22}$.

Dos nuevas propuestas a favor de la ocupación de las islas Chafrinas serán manifestadas a la reina Isabel II con dos memorias realizadas en 1844 y 1845, la primera a partir de un nueva exploración del archipiélago por parte del capitán de navío Luis Hernández Pinzón, comandante del navío de guerra Isabel II y, un año después, ante el progresivo avance de los franceses, por el brigadier de Ingenieros Miguel Santillana y Díez ${ }^{23}$. Este último tenía encomendada la misión de redactar un informe sobre las obras de defensa necesar ias en el caso de que las islas fuesen ocupadas. Todo este interés del gobier no español estaba provocado por la preocupación que les estaba causando el a vance de Francia en Argelia. Estos preámbulos darán paso a los preparativos para una aproximación definitiva, comienzan en el verano de 1847 y en diciembre el capitán general Francisco Serrano se hace cargo de la expedición que incor porará las islas Chafar inas a territorio español el día 6 de enero de 1848.

\section{LA OCUPACIÓN DE LAS ISLAS CHAFARINAS EL 6 DE ENERO DE 1848}

La Real Orden de 26 de junio de 1847 ob liga a estar preparados para el inmediato anuncio de que las islas Chafrinas debían ser ocupadas. El motivo que precipitó los acontecimientos fue la sospecha de que los franceses rondaban las

${ }^{22}$ Censo-guía de Archivos de España e Iberoamérica. Ministerio de Cultura.

${ }^{23}$ Visita del brigadier Miguel Santillana en 1845 (AGMM) Fondo África, R 823.6. 
islas con la intención de desembarcar en ellas. Ya existía cierto temor por parte de España ante la expansión de los franceses en África, por lo que el gobier no estaba dispuesto a poner fr eno a este a vance que hacía pelig rar la anexión de nuevos territorios en el Mediterráneo. El gobernador de la plaza de Melilla el 22 de noviembre de 1847 y a había dado par te de que el vapor de guer ra francés Veloz había estado r econociendo las Chafar inas y que, según algunas noticias llegadas a su gobierno, trataba de negociarlas con el emperador de Mar ruecos. Para verificar el alcance del asunto se comisionó a un jefe de confianza,mientras el gobierno nombraba al responsable de la futura misión en las costas africanas. Cuando estas noticias llegan al gobier no de España y a S.M. la reina, una Real Orden de 10 de diciembre del mismo año, se dictamina que las islas sean ocupadas. Para afianzar la misión se pidier on todas las noticias y da tos estadísticos necesarios para que la operación se desarrollara con éxito.

España mostraba gran interés por la capacidad que albergaba el puerto de estas islas, pues contemplaban la posibilidad de que acogiera buques de todos los portes por lo que quedarían al abrigo de los más fuertes temporales debido a la gran calidad de sus fondeader os. Esta valoración atribuida a las condiciones de los puertos quizá fue excesiva, un hecho que junto a la idea de la existencia de agua potable en las islas animaría a España a la ocupación.

El gobierno puso a disposición del capitán general don Francisco Serrano Caballero ${ }^{24}$ dos vapores de guerra, un escuadrón de Caballería que debía pasar a Melilla, un batallón de Infantería y otro del Regimiento Fijo de Ceuta con destino también a dicha Plaza. Posteriormente, se destinaron con el mismo objeto un vapor, un pailebot, un falucho de guerra y una batería de montaña del tercer departamento. Se reclutaron también grupos de confinados de oficio de los presidios de Granada y Málaga, una compañía del Reg imiento de Ingenieros, dos blockaus y el parque de este cuerpo que se hallaba en Ceuta.

Después de todas las disposiciones puestas en marcha, el general Serrano dictó las órdenes per tinentes para que comenzasen los pr eparativos necesarios para la expedición a través de los Cuerpos de Artillería, el de Ingenieros y por la Hacienda Militar. Serrano sale de Granada el día 19 de diciembr e hacia Málaga

\footnotetext{
${ }^{24}$ Gran Cruz de la Real y Militar Orden de San Ernando y de Isabel la Cá́lica condecorado con varias de $1^{\mathrm{a}}, 2^{\mathrm{a}}$ y $3^{\mathrm{a}}$ clase de San F ernando y otras por acciones de Guer ra, teniente general de los Ejércitos Nacionales, senador del reino y capitán general de los reinos de Granada y Jaén.
} 
para supervisar los trámites y pr eparativos que ya se habían puesto en marc ha junto al subinspector de Ingenier os, el comandante general de Artillería y el intendente militar. La misión requería todo tipo de previsiones, pues estaba dirigida a un lugar al que habría que transpor tar incluso el agua, por lo tanto, se contrataron los víveres, utensilios para cuar teles y hospitales y los barcos que habían de transpor tarlos; se procedió a construir explanadas, barracones para cuarteles, cuerpos de guardia, almacenes de pólvora y víveres y todo lo necesario perteneciente a Ingenieros y Artillería.

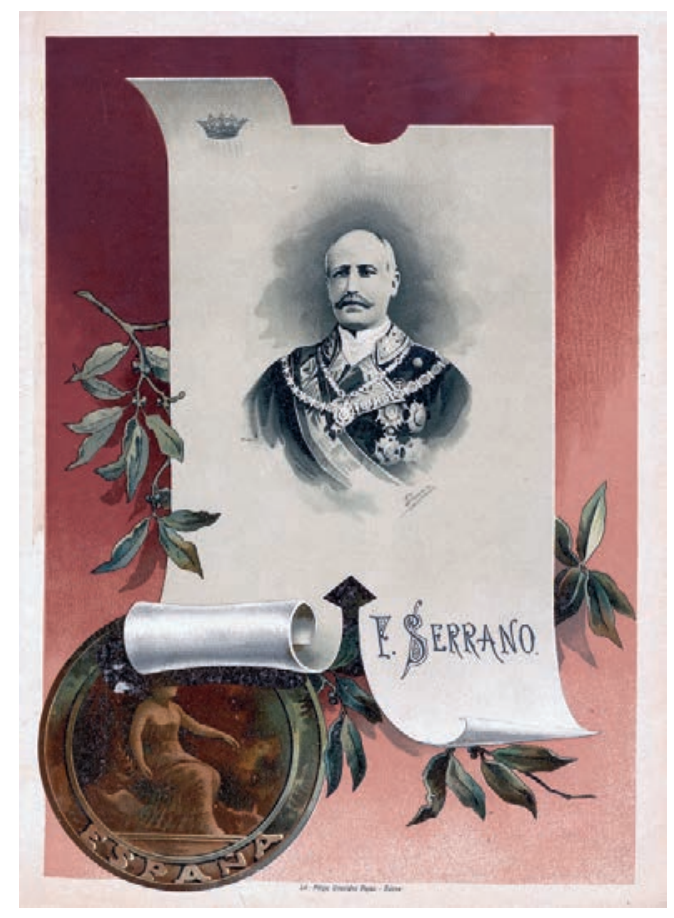

El general Serrano. FCOML.

El día 4 de enero todo estaba dispuesto para la traesía hacia las Chafarinas, la escuadra formada por diferentes barcos contaba con los v apores de guer ra Piles y Vulcano que remolcarían al bergantín Isabel I y al místico de guer ra Flecha. En siete transportes mercantes se cargaron los víveres, las municiones, los parques y material de artillería, los barracones, garitas, etc., también dos obuses de a siete y cuatro de montaña largos que se embarcaron con el personal correspondiente. Dos compañías de preferencia del Regimiento de Infantería de África, cincuenta confinados para realizar los trabajos una vez desembarcados, varios 
carpinteros de Málaga que voluntariamente se presentaron a la expedición, los empleados de la Hacienda Militar y de los Cuepos de Artillería e Ingenieros y, el capitán general Serrano acompañado por un séquito formado por jefes, oficiales, ayudantes de campo y el que sería gobernador de las islas.

Un fuerte temporal acompañaría a la escuadra destinada a ocupar las islas Chafarinas desde la salida del puerto de Málaga el día 4 de enero, unas condiciones meteorológicas que presagiaba una travesía más complicada mar adentro y que ocasionaría algunos incon venientes a la tribulación, dificultades que serían subsanadas a partir de las decisiones tomadas por los comandantes de los bques. A la media noche llegaría la calma y el viaje trascurrió sin problemas, el Piles y sus transportes fondearía en la rada de Melilla el día 5 por no poder alcanzar las islas, sin embargo, sí llegó elVulcano, embarcación más ligera que salió de Málaga con antelación para fondear a las nueve de la noche en las Chafarinas.

Ya reunidos y anclados convenientemente los buques frente al archipiélago, el general Serrano acompañado de su comitiva desembarcó en la isla central y tras de él, lo harían las tropas de Infantería y Artillería con las cuatro piezas de montaña formadas en batalla frente a la costa de Áfr ica. Serrano proclamó la posesión en cada una de las islas en nombr e de su majestad la r eina de España Da Isabel II y , seguidamente, se produjeron las salvas por la tropa y los buques de la armada para finalizar bautizando las islas con los nombres de Isabel II la del centro; del Rey la del este y del Cong reso la del oeste y por pa trones la adoración de los Santos Reyes, quedando después instalada la guarnición correspondiente en las islas.

Después de la toma de posesión se procedió a desembarcar todo el material transportado en los buques. La noche del 6 de enero, el general Serrano en el vapor Vulcano se dirige a Málaga con el capitán de Caballería D José Chinchilla, el ayudante de campo que trasladaba el par te al gobierno de S.M. la reina y el teniente D. Luis de laTorre, una comisión de carácter oficial que estaba destinada al embarque de todos los efectos disponib les para ser enviados a las islas desde Málaga. De nuevo les sorprende un fuerte temporal que los lleva hasta la costa española con algunas a verías en los tubos de sus calader os, de nuevo las malas condiciones climatológicas van a dificultar los embarcos y desembarcos de los materiales que debían ser enviados a las recién tomadas islas.

Mientras, en la isla de Isabel II se trabajaba de forma incesante para acondicionarla e instalar las principales defensas, pero el fuerte viento impedía armar los barracones y establecer las tiendas de campaña que tuvieron que ser improvisadas con velas y palos de los buques. El temporal arreció tanto que obligó a suspender 
los desembarcos, se había creado una situación muy incómoda para desarrollar los trabajos, por ello, los jefes de Ingenieros se dedicaron a trazar baterías y cocinas, así como a la cata de pozos en busca de agua potable. El tiempo empeoraba y el viento el granizo y la lluvia intensa dejó sin com unicación a los buques con la isla por lo que hubo que esperar para reanudar las labores ya empezadas. Las condiciones se endurecían en la mar, cada vez más gruesa, por ello, los buques tuvieron que dar fondo a sus segundas anclas. Estas condiciones hicieron que en un momento determinado del mediodía las lanchas de los navíos de guerra tuvieran que socorrer al Místico correo de Melilla que se encontraba anclado entr e la isla del Rey y la de Isabel II. El falucho donde estaba embarcada la pólvora pidió auxilio al romper sus amarras y quedó después asegurado con un calabr ote de cadena que le facilitó el Piles. Continuando en circunstancias tan ad versas fue necesario que los v apores buscaran otro fondeadero que les fuese más favorable al sur del Congreso, pues los golpes de mar que entraban por ambos fieos arrastraban hacia tierra a las embarcaciones. En la isla, en esta noche dura, se abatieron las tiendas, cayeron las garitas y las barracas provisionales hechas de tabla, fue necesario estar toda la noche sosteniéndolas porque el viento y el agua amenazaban destr uirlas. De medianoche en adelante calmó el aire y la mar se aquietó,aunque siguió lloviendo, el amanecer del día diez de enero se terminó de transportar los materiales que aún permanecían en los buques y así continuar con las tareas necesarias en Isabel II, la isla que acogería a la futura población de las Chafarinas.

\section{BLIOGRAFÍA:}

ARREDONDO, Ma Soledad. "Relaciones entre España y Francia en los siglos XVI y XVII: testimonio de una enemistad". Universidad Complutense de Madrid. BRAVO NIETO, Antonio (2004). "El Gran Capitán y la España de los Re yes Católicos”. Exposición El Gran Capitán y la España de los Reys Católicos. 'Melilla: Fundación Gaselec.

BRAUDEL, Fernand (2005). La economía del Mediter ráneo del siglo XVII . Colección Mediterráneo Económico no 7: Mediterráneo e Historia Económica. Caja Rural Inter mediterránea, Cajamar. Instituto de Estudios Socioeconómicos de Cajamar.

CALDERÓN VÁZQUEZ, Francisco José (2008): Fronteras, identidad, conflicto e interacción. Los Presidios españoles en el norte africano. 
CÁMARA, Alicia. Las for tificaciones de Melilla en el sistema defensiv o de la Monarquía española. Siglos XVI a XVIII.

CASTRO MARTOS, Ma Pilar: "Proyección de España en África: la documentación de la Sección de Estado del Archivo Histórico Nacional"

GARCÍA DE CORTÁZAR, F.; GONZÁLEZ VESGA, J. M.: Breve historia de España, 1995, Barcelona

SOLA, Emilio (2005): “Apéndice al epistolario de los Doria de R.Vargas-Hidalgo: Juan Andrea Doria de guardia por Berbería, en el otoño de 1562”. Archivo General de Simancas / Sección: Estado. Legajo: 486. Documentos: 57, 58.

MAESTRO CASTAÑEDA, Juan Carlos (2002): “D. Juan José Navarro, Marqués de la Victoria: entre reformista y resentido". Universidad de Valladolid.

MARIÑAS OTERO, Eugenio (1998): "Las Plazas Menores de soberanía española en África”. Mititaria. Revista de Cultura Militar, $n^{\circ} 12$. Servicio de Publicaciones. Universidad Complutense de Madrid.

MARTÍNEZ MONTIEL, Luis Francisco: "La maqueta de Cádiz, algunos apuntes sobre la construcción y su autor"

MORALES, Gabriel de (1921). Efemérides de la Historia de Melilla (1497-1913). Melilla: Imprenta El Telegrama del Rif.

MUÑOZ CORBALÁN, Juan Miguel: "Estrategia de la corona española para la conservación de los pr esidios menores africanos durante el siglo XVIII (1)" Profesor Ayudante del Departamento de Arte. Universitat Autónoma de Barcelona.

PÉREZ, José: “El Mediterráneo en la Historia”. Université de Bourdeaux III.

RABANAL YUS, Aurora (1993): "En torno a los llamados Presidios Menores, o plazas de Melilla, Peñón de Vélez de la Gomera y Alhucemas, en el siglo XVIII. Anuario del Departamento de Historia y Teoría del Arte. Universidad Autónoma de Madrid. Volumen V.

SÁIZ DE BARANDA, Pedro; SALVÁ, Miguel (1845). "La posesión de las islas Chafarinas”. Boletín de la Real Academia de la Historia. Madrid.

THOMPSON, I. A. A. (2006): "Las galeras en la política militar española en el Mediterráneo durante el siglo XVI”. KeeleUniversity. School of History. Staffordshire, UK.

VODOPICH, Matheo. "Relación y descripción individual del presidio y plaza de Melilla”. Comisión de Real Orden, en 23 de julio del 1763. 